\title{
Cholinergic Neurons Excite Cortically Projecting Basal Forebrain GABAergic Neurons
}

\author{
Chun Yang, James T. McKenna, Janneke C. Zant, Stuart Winston, Radhika Basheer, and Ritchie E. Brown \\ Laboratory of Neuroscience, VA Boston Healthcare System and Harvard Medical School, Brockton, Massachusetts 02301
}

The basal forebrain $(\mathrm{BF})$ plays an important role in the control of cortical activation and attention. Understanding the modulation of $\mathrm{BF}$ neuronal activity is a prerequisite to treat disorders of cortical activation involving BF dysfunction, such as Alzheimer's disease. Here we reveal the interaction between cholinergic neurons and cortically projecting BF GABAergic neurons using immunohistochemistry and whole-cell recordings in vitro. In GAD67-GFP knock-in mice, BF cholinergic (choline acetyltransferase-positive) neurons were intermingled with GABAergic $\left(\mathrm{GFP}^{+}\right)$neurons. Immunohistochemistry for the vesicular acetylcholine transporter showed that cholinergic fibers apposed putative cortically projecting GABAergic neurons containing parvalbumin (PV). In coronal BF slices from GAD67-GFP knock-in or $P V$-tdTomato mice, pharmacological activation of cholinergic receptors with bath application of carbachol increased the firing rate of large $\left(>20 \mu \mathrm{m}\right.$ diameter) $\mathrm{BF} \mathrm{GFP}^{+}$and PV (tdTomato + ) neurons, which exhibited the intrinsic membrane properties of cortically projecting neurons. The excitatory effect of carbachol was blocked by antagonists of $M_{1}$ and $M_{3}$ muscarinic receptors in two subpopulations of BF GABAergic neurons [large hyperpolarization-activated cation current $\left(I_{\mathrm{h}}\right)$ and small $I_{\mathrm{h}}$, respectively]. Ion substitution experiments and reversal potential measurements suggested that the carbachol-induced inward current was mediated mainly by sodium-permeable cation channels. Carbachol also increased the frequency of spontaneous excitatory and inhibitory synaptic currents. Furthermore, optogenetic stimulation of cholinergic neurons/fibers caused a mecamylamine- and atropine-sensitive inward current in putative GABAergic neurons. Thus, cortically projecting, BF GABAergic/PV neurons are excited by neighboring BF and/or brainstem cholinergic neurons. Loss of cholinergic neurons in Alzheimer's disease may impair cortical activation, in part, through disfacilitation of $\mathrm{BF}$ cortically projecting GABAergic/PV neurons.

Key words: brain slices; optostimulation; patch-clamp; transgenic mice

\section{Introduction}

Impairments of cortical activation are observed in many neurological and psychiatric disorders (Herrmann and Demiralp, 2005; Brown et al., 2012). Improved treatment of these diseases requires a precise understanding of how ascending subcortical projections interact to mediate state-dependent changes in brain activity. One such subcortical projection arises in the basal forebrain (BF). Studies in animals have shown that pharmacological inhibition (Cape and Jones, 2000) or neurotoxic lesions (Buzsaki et al., 1988; Burk and Sarter, 2001; Kaur et al., 2008; Fuller et al., 2011) of this region cause dramatic impairments in cortical activation and attention. Furthermore, in humans with Alzheimer's disease, degeneration of regions of the $\mathrm{BF}$ containing cholinergic

Received July 22, 2013; revised Jan. 7, 2014; accepted Jan. 10, 2014

Author contributions: C.Y., J.T.M., J.C.Z., R.B., and R.E.B. designed research; C.Y., J.T.M., J.C.Z., S.W., R.B, and R.E.B. performed research; C.Y., J.T.M., and R.E.B. analyzed data; C.Y., J.T.M., and R.E.B. wrote the paper.

This work was supported by VA Merit Awards to R.W. McCarley and R.B.; and by National Institute of Mental Health Grants R01 MH039683 and R21 MH094803; National Heart, Lung, and Blood Institute Grant HL095491; and National Institute of Neurological Disorders and Stroke Grant R21 NS079866.

The authors declare no competing financial interests.

Correspondence should be addressed to Ritchie E. Brown, In Vitro Neurophysiology Section, Laboratory of Neuroscience, Department of Psychiatry, VA Boston Healthcare System and Harvard Medical School, VA Medical Center Brockton, Research 151C, 940 Belmont Street, Brockton, MA 02301. E-mail: Ritchie_Brown@hms.harvard.edu.

DOI:10.1523/JNEUROSCI.3235-13.2014

Copyright $\odot 2014$ the authors $\quad 0270-6474 / 14 / 342832-13 \$ 15.00 / 0$ neurons is one of the earliest signs of the disease (Teipel et al., 2011; Grothe et al., 2012).

Electrical stimulation of the caudal BF promotes highfrequency cortical electroencephalogram oscillations via release of acetylcholine in the cortex (Metherate et al., 1992; Metherate and Ashe, 1993). Accordingly, drugs targeting the cholinergic system have been proposed as treatments for disorders involving abnormal cortical activation such as Alzheimer's disease and schizophrenia (Conn et al., 2009; Jones et al., 2012). However, lesions of $\mathrm{BF}$, which preferentially target noncholinergic neurons, have effects on cortical activation and attention, which are at least as potent as selective lesions of cholinergic neurons (Burk and Sarter, 2001; Kaur et al., 2008), suggesting that noncholinergic BF neurons are equally important.

In addition to cholinergic neurons, the $\mathrm{BF}$ cortical projection includes a substantial proportion of GABAergic neurons (Freund and Meskenaite, 1992; Gritti et al., 1993, 2003; Henny and Jones, 2008; McKenna et al., 2013), many of which contain the calciumbinding protein, parvalbumin (PV; Gritti et al., 2003). These PVpositive, BF GABAergic neurons are of particular interest since they are projection neurons that target GABAergic neocortical interneurons and pyramidal neurons (Freund and Meskenaite, 1992; Gritti et al., 2003; Henny and Jones, 2008). Juxtacellular labeling following single-unit recordings in vivo identified a subpopulation of BF GABAergic neurons (Manns et al., 2000; Has- 
sani et al., 2009) or PV neurons (Duque et al., 2000), which are fast firing and increase their firing rate further during cortical activation. Furthermore, we recently found that optogenetic stimulation of BF PV neurons preferentially entrains fast cortical oscillations (Kim et al., 2011). Together, these findings suggest that these neurons may play an important role in the control of cortical activation.

Cholinergic BF projection neurons exhibit local axon collaterals terminating onto other BF neurons, including GABAergic neurons (Záborszky et al., 1986; Záborszky and Duque, 2000). In addition, the BF receives a cholinergic input from the brainstem (Semba et al., 1988). However, the functional effect of acetylcholine release within the $\mathrm{BF}$ on the $\mathrm{GABAergic} / \mathrm{PV}^{+}$projection to the neocortex is unknown, due to difficulties in identification. Here, we use recently validated genetically modified mice expressing fluorescent markers in GABAergic and PV neurons (McKenna et al., 2013) to determine the relationship between these two important neurotransmitter systems involved in cortical activation and attention.

\section{Materials and Methods}

Animals. To identify BF GABAergic neurons, we used heterozygous GAD67-GFP knock-in mice (McKenna et al., 2013). Although heterozygous animals lack one copy of the Gad1 gene encoding GAD67, the sleep-wake behavior and cortical rhythms of these animals are indistinguishable from those of wild-type animals (Chen et al., 2010; McNally et al., 2011). Male, heterozygous GAD67-GFP knock-in mice on a SwissWebster background were crossed in-house with wild-type SwissWebster mice (Charles River). To record from PV-containing neurons, we crossed PV-Cre mice (Strain 008069; Jackson Laboratories) with a Cre-reporter strain (Strain 007905; Jackson Laboratories), resulting in mice expressing red (tdTomato) fluorescence in neurons expressing PV (PV-tdTomato mice; McKenna et al., 2013). To investigate the endogenous effect of acetylcholine on BF GABAergic neurons, we used mice constitutively expressing channelrhodopsin 2 (ChR2) under the control of the ChAT promoter (Zhao et al., 2011). Male, hemizygous ChATChR2-EYFP mice (Strain 014546; Jackson Laboratories) were crossed with female wild-type Swiss-Webster mice.

Since the extensive myelination in the BF after postnatal day 22 (P22) makes infrared visualization of the neurons extremely difficult, for in vitro electrophysiological recordings we used juvenile (12- to 22-d-old) animals. Adult animals were used for immunohistochemical staining and mapping. Mice were housed under constant temperature and a $12 \mathrm{~h}$ light/dark cycle (7:00 A.M./7:00 P.M.), with food and water available ad libitum. All experiments conformed to US Veterans Administration, Harvard University, and the US National Institutes of Health guidelines.

Target area within the BF. For both immunohistochemical staining and electrophysiological experiments, we focused on intermediate areas of the basal forebrain [substantia innominata (SI), horizontal limb of the diagonal band ( $\mathrm{HDB})$, magnocellular preoptic nucleus (MCPO) and ventral pallidum (VP)], where previous studies in the rat (Rye et al., 1984; Gritti et al., 2003; Henny and Jones, 2008) have found neurons projecting to the neocortex. Our analysis did not include the rostral aspect of BF (medial septum and vertical limb of the diagonal band), a portion of which contains neurons projecting to the hippocampus or the caudal magnocellular basal nucleus, although $\mathrm{GFP}^{+}$neurons were also located in these areas. Therefore, our investigations were largely of intermediate levels of the basal forebrain.

Immunohistochemistry methods. Immunohistochemical staining and analysis were performed as in our previous study (McKenna et al., 2013). Mice were deeply anesthetized with sodium pentobarbital $(50 \mathrm{mg} / \mathrm{ml})$, exsanguinated with saline solution, and perfused transcardially with $10 \%$ buffered formalin. Brains were postfixed for $4 \mathrm{~h}$ and then transferred to a $30 \%$ sucrose solution for $48 \mathrm{~h}$ at $4^{\circ} \mathrm{C}$. The $40 \mu \mathrm{m}$ sections were cut on a freezing microtome and collected into four wells of PBS. Tissue was mounted onto chrome-alum gelatin-coated slides, dried, and coverslipped using Vectashield HardSet Mounting Medium (H-1400; Vector
Laboratories). Staining and quantification was conducted in four animals. For each stain [ChAT, vesicular acetylcholine transferase (vAChT), and PV], we quantified three representative coronal section levels per animal (measured from bregma: rostral, $0.38 \mathrm{~mm}$; medial, $0.014 \mathrm{~mm}$; and caudal, $-0.10 \mathrm{~mm}$ ) using Neurolucida software (version 8; MicroBrightField) and an Olympus BX51 microscope.

Choline acetyltransferase immunohistochemistry. To determine the relative location of cholinergic and GABAergic neurons in GAD67-GFP knock-in mice, as well as to confirm that ChR2-enhanced yellow fluorescent protein (EYFP) was correctly localized to cholinergic neurons in ChAT-ChR2-EYFP mice, we performed ChAT staining. Coronal slices from one well were placed in a blocking solution, and then incubated in rabbit anti-choline acetyltransferase [ChAT (the synthetic enzyme for acetylcholine) 1:200; AB143; Millipore (http://antibodyregistry.org, identification (ID) number 2079760] for 2 nights at $4^{\circ} \mathrm{C}$. After incubation, tissue was rinsed and treated for $3 \mathrm{~h}$ at room temperature (RT) in secondary antibody, donkey anti-rabbit IgG conjugated with Alexa Fluor 594 (red; 1:100; A21207; Invitrogen).

$v A C h T$ and $P V$ immunohistochemistry. To determine whether cholinergic varicosities are located in the vicinity of GABAergic and $\mathrm{PV}^{+}$ neurons, we performed staining for PV and vAChT in GAD67-GFP knock-in mice. Coronal BF slices were treated as follows: (1) incubated in goat anti-vAChT [1:500; AB1578 (now listed as AG260); Millipore; http://antibodyregistry.org, ID:10000324] for 1 night at $4^{\circ} \mathrm{C}$; (2) treated for $3 \mathrm{~h}$ at RT in secondary antibody, donkey anti-goat IgG conjugated with Alexa Fluor 594 (red; 1:100; A11058; Invitrogen); (3) incubated in rabbit anti-PV (1:200; PA1-933; Thermo Scientific; Antibody Registry, http://antibodyregistry.org, ID number $2173898)$ for $40 \mathrm{~h}$ at $4^{\circ} \mathrm{C}$; (4) treated with donkey anti-rabbit (1:300; 711-005-152; Jackson Immunoresearch) for $2 \mathrm{~h}$ at RT; (5) treated with streptavidin Alexa Fluor 350 (blue; 1:100; S-11249; Invitrogen) for $1 \mathrm{~h}$ at RT; and, finally, (6) to amplify the blue signal, sections were treated with primary antibody biotinylated goat anti-streptavidin (1: 100; BA-0500; Vector Laboratories) for $45 \mathrm{~min}$ at RT. Sections were then restained with Streptavidin Alexa Fluor 350 (1:100) for $30 \mathrm{~min}$ at RT.

Cell mapping and photography of GABAergic $\left(G F P^{+}\right)$neurons, cholinergic neurons, and $P V^{+}$neurons. The perimeter and landmarks of $B F$ were first traced at a low magnification $(10 \times)$. Neuronal location was then plotted at higher magnifications $(20-40 \times)$ and imposed on the lowmagnification Neurolucida sketches. The distribution of labeled neurons was determined using a mouse brain atlas (Franklin and Paxinos, 2008). We mapped the representative case that best matched the template subnuclei boundaries. Once tracing and cell plotting was completed in Neurolucida, this sketch was placed on top of the Adobe Illustrator templates (using the "Transparency" tool). Symbols were then replotted in Adobe Illustrator (CS5, version 15.1.0) superimposed on the Neurolucida cell mapping.

$\mathrm{GFP}^{+}$neurons in GAD67-GFP knock-in mice and $\mathrm{EYFP}^{+}$neurons in ChAT-ChR2-EYFP mice were identified by the presence of green fluorescence (excitation/emission ratio, 488:509 nm). $\mathrm{ChAT}^{+}$and $\mathrm{vAChT}^{+}$ cells were identified by the presence of red fluorescence (excitation/emission ratio, 590:617 nm), and $\mathrm{PV}^{+}$neurons were identified by blue fluorescence (excitation/emission ratio, 343:442 nm). Digital images of fluorescently labeled neurons were captured using a deconvolution Zeiss Axioplan 2 microscope and the Slidebook system (3i: Intelligent Imaging Innovations). Image clarity was enhanced by adjusting the contrast and brightness in Slidebook and/or Adobe Photoshop image-processing software. Individual low-power photomicrographs, as well as all figures that include multiple panels, were assembled using Adobe Photoshop (CS5, version 12.1, ×64), except for cellular mapping (Fig. 1G,H), where they were assembled using Adobe Illustrator (CS5, version 15.1.0).

Preparation of BF slices for electrophysiological recordings. Mice were deeply anesthetized with isoflurane and then decapitated. Two 300$\mu \mathrm{m}$-thick coronal BF slices were cut rostrocaudally between 0.26 and $-0.22 \mathrm{~mm}$ from bregma (Franklin and Paxinos, 2008). After slicing, they were placed into ACSF containing the following (in $\mathrm{mm}$ ): 124 $\mathrm{NaCl}, 1.8 \mathrm{KCl}, 25.6 \mathrm{NaHCO}_{3}, 1.2 \mathrm{KH}_{2} \mathrm{PO}_{4}, 2 \mathrm{CaCl}_{2}, 1.3 \mathrm{MgSO}_{4}$, and 10 glucose (osmolarity, $300 \mathrm{mOsm}$ ), saturated with $95 \% \mathrm{O}_{2} / 5 \% \mathrm{CO}_{2}$ 
for $>1 \mathrm{~h}$ at room temperature before being transferred to the recording chamber and superfused with warmed $\operatorname{ACSF}\left(32^{\circ} \mathrm{C}\right)$ at $2-3$ $\mathrm{ml} / \mathrm{min}$.

Whole-cell recordings. Electrophysiological recordings focused on intermediate/caudal parts of the $\mathrm{HDB}$ and $\mathrm{MCPO}$, where our previous study (McKenna et al., 2013) found that large GABAergic and GABAergic/PV ${ }^{+}$ neurons are most highly concentrated. Putative cortically projecting neurons were identified in vitro based on their large size (Gritti et al., 2003) and typical intrinsic membrane properties (McKenna et al., 2013). GABAergic $\left(\mathrm{GFP}^{+}\right)$neurons in GAD67-GFP knock-in mice or $\mathrm{PV}^{+}$neurons in $P V$ tdTomato mice were selected for recording based on their expression of the fluorescent marker. Neurons were photographed before recording using a Hamamatsu ORCA-AR CCD camera. Long-axis cell diameter was measured from these images and calibrated using a standard grid. For most experiments, patch pipettes $(3-6 \mathrm{M} \Omega$ ) were filled with intracellular solution containing the following (in $\mathrm{mm}$ ): 130 potassium gluconate, $5 \mathrm{NaCl}, 2$ $\mathrm{MgCl}_{2}, 10$ HEPES, 0.1 EGTA, $2 \mathrm{Na}_{2}$ ATP, 0.5 NaGTP, 4 MgATP, 1 spermine, and 0.5\% biocytin, pH 7.25 with $\mathrm{KOH}$ (280 mOsm). Membrane potential measurements were adjusted for a $-15 \mathrm{mV}$ liquid junction potential between pipette and bath solutions (calculated using pClamp 9.0 software). For recording of IPSCs, potassium gluconate was replaced with $\mathrm{KCl}$. Recordings were made using a Multiclamp 700B amplifier and pClamp 9.0 software (Molecular Devices). Bridge balance was adjusted after gaining access to the whole cell and maintained throughout the experiment. Recordings were accepted if action potentials were overshooting and series resistance changed by $<10 \%$ during the experiment. In voltage-clamp recordings, series resistance was 6-15 $\mathrm{M} \Omega$ and was not compensated. Continuous recordings of membrane voltage and current were made using a MiniDigi 1A system and Axoscope 9.2 software (Axon instruments) with a sampling frequency of $1 \mathrm{kHz}$.

Characterization of intrinsic membrane properties. As described previously (McKenna et al., 2013), a series of 1-s-long hyperpolarizing and depolarizing current pulses were applied in current-clamp from the resting membrane potential (RMP). The size of the first hyperpolarizing step was titrated according to the input resistance of the neuron so that the negative peak of the membrane potential during the step reached -100 $\mathrm{mV}$. Progressively more depolarizing current steps (in increments onefifth the size of the initial step) were applied until the firing rate did not increase further. The percentage of depolarizing sag was determined from the largest hyperpolarizing step as [(steady-state voltage at end of the step $-\mathrm{RMP}) /($ peak voltage $-\mathrm{RMP})] \times 100$.

Pharmacological experiments to determine the effect of carbachol on firing frequency and membrane potential. Carbachol (50 $\mu \mathrm{M})$ was bath applied for $2 \mathrm{~min}$. Action potential frequency was determined on-line in $15 \mathrm{~s}$ bins by crossing a threshold set at $0 \mathrm{mV}$ (Clampex 9.0 software; Molecular Devices). To determine the receptor mediating the effect of carbachol, the cholinergic antagonists atropine (muscarinic antagonist; 5 $\mu \mathrm{M})$, pirenzepine dihydrochloride $\left(0.1,1,10\right.$, and $50 \mu \mathrm{M} ; \mathrm{M}_{1}$ receptor antagonist), and 4-diphenylacetoxy- $N$-methylpiperidine methiodide (4-DAMP; $0.3,1$, and $3 \mu \mathrm{M} ; \mathrm{M}_{3}$ receptor antagonist) were bath applied at least 5 min before the application of carbachol. Small $200 \mathrm{~ms}$ hyperpolarizing current steps were applied every $15 \mathrm{~s}$ to monitor input resistance. Drugs were purchased from Sigma-Aldrich. Stock solutions were pre- pared in distilled water and stored at $-4^{\circ} \mathrm{C}$. The concentrations used were determined by conducting a literature search for both known receptor binding specificity values and previous experimental usage of drugs in in vitro slice preparations (Shen and Johnson, 2000; Busch and Borda, 2003; Pressler et al., 2007). We note that binding affinities of antagonists measured in expression systems can be used only as a guide to effective concentrations in brain slice experiments since the steady-state concentration in the immediate vicinity of the receptors within the slice are likely to be much lower than the concentration in the perfusate. In addition, post-translational modifications or accessory protein coupling in situ can modify binding affinity. Nonetheless, differences in responsiveness and concentration dependence of antagonism are suggestive of differences in the receptor subtype involved.

Voltage-clamp experiments to investigate the ion channels involved in the carbachol response. Neurons were clamped at $-60 \mathrm{mV}$. To determine whether the carbachol responses reversed at the $\mathrm{K}^{+}$equilibrium potential, slow (4 s) voltage ramps from -120 to $-60 \mathrm{mV}$ were applied at $30 \mathrm{~s}$ intervals. To determine whether the carbachol response was mediated by mixed cation channels, slices were incubated in a modified $\mathrm{Ca}^{2+}$-free ACSF (in mm: $124 \mathrm{NaCl}, 1.8 \mathrm{KCl}, 25.6 \mathrm{NaHCO}_{3}, 1.2 \mathrm{KH}_{2} \mathrm{PO}_{4}, 2 \mathrm{MgCl}_{2}$, $1.3 \mathrm{MgSO}_{4}$ and 10 glucose) containing $500 \mathrm{~nm}$ tetrodotoxin (TTX) and tested with a ramp from -100 to $40 \mathrm{mV}$ ( $20 \mathrm{~s}$ duration) every $2 \mathrm{~min}$. To determine the involvement of $\mathrm{Na}^{+}$in the carbachol response, the same voltage ramps from -100 to $40 \mathrm{mV}$ were applied in $\mathrm{Ca}^{2+}$-free solution where most of the extracellular sodium was replaced by the impermeant ion $\mathrm{N}$-methyl-D-glucamine [NMDG; low extracellular $\mathrm{Na}^{+}-\mathrm{Ca}^{2+}$-free solution as follows (in mM): $127 \mathrm{NMDG}, 1.8 \mathrm{KCl}, 25.6 \mathrm{NaHCO}_{3}, 1.2$ $\mathrm{KH}_{2} \mathrm{PO}_{4}, 2 \mathrm{MgCl}_{2}, 1.3 \mathrm{MgSO}_{4}$, and 10 glucose, osmolarity $\left.300 \mathrm{mOsm}\right]$.

Measurement and analysis of synaptic currents. Spontaneous postsynaptic currents were recorded without TTX, while miniature postsynaptic 
currents were recorded in the presence of $500 \mathrm{nM}$ TTX. EPSCs were recorded with $10 \mu \mathrm{M}$ GABAzine in the bath to block $\mathrm{GABA}_{\mathrm{A}}$ receptormediated currents. IPSCs were recorded in the presence of $20 \mu \mathrm{M}$ DNQX and $50 \mu \mathrm{M}$ AP-5 to block glutamatergic AMPA and NMDA receptormediated currents, respectively. To enhance the resolution of $\mathrm{GABA}_{\mathrm{A}}$ receptor-mediated events, we enhanced the driving force for chloride entry by using a $\mathrm{KCl}$-based pipette solution. A $1 \mathrm{~min}$ period immediately before carbachol application and a $1 \mathrm{~min}$ period $2 \mathrm{~min}$ after the application of carbachol, when the peak effect was apparent, were used for statistical analysis (Igor software). Only well resolved events with amplitudes $>10 \mathrm{pA}$ were analyzed.

Optical stimulation of cholinergic neurons. Brain slices were prepared from 13- to 22-d-old ChAT-EYFP-ChR2 mice, as described above. Cholinergic neurons were selected for recording based on their expression of EYFP. Putative GABAergic neurons were determined by their fluorescent-negative property, morphology, and electrophysiological properties (McKenna et al., 2013). A BLS-series BioLED light source (Mightex) connected to the microscope via a Mightex multiwavelength beam combiner and controlled by a BioLED light source control module was used to deliver $470 \mathrm{~nm}$ wavelength blue light to the brain slices through the full field of a $40 \times$ water-immersion objective attached to the microscope, illuminating the area surrounding the recorded neuron. The light power delivered to the tissue was $30 \mathrm{~mW} / \mathrm{mm}^{2}$, which was determined by dividing the power of light under the objective measured with a slim photodiode power sensor (Sensor S130C; Thorlabs) by the area of the objective field $\left(0.26 \mathrm{~mm}^{2}\right.$ for the W N-Achroplan, $40 \times$ Zeiss objective). The response of cholinergic neurons to light stimulation was recorded in regular ACSF, while the response of GABAergic-like neurons to light stimulation was recorded in the presence of $20 \mu \mathrm{M}$ DNQX plus 50 $\mu \mathrm{M}$ AP-5 plus $10 \mu \mathrm{M}$ GABAzine to block indirect effects of light stimulation mediated through the stimulation of glutamatergic and GABAergic neurons. Since cholinergic neurons have prominent A-type potassium currents, which limit the rate of depolarization and long-lasting action potentials, we used a pulse width of $10 \mathrm{~ms}$ to ensure reliable elicitation of action potentials in response to light. Atropine and mecamylamine hydrochloride (nicotinic receptor antagonist; $100 \mu \mathrm{M}$; Sigma) were bath applied to determine the receptor types in mediating the response.

Statistics. Data are presented as the mean \pm SEM. Neuroanatomical percentages of overall counts of $\mathrm{BF} \mathrm{ChAT}^{+}$cells were analyzed using one-way ANOVA, followed by a pairwise independent $t$ test comparison among the different BF subnuclei, using Bonferroni's correction. The effect of the drug or light stimulation on membrane potential/current or input resistance were assessed by comparing membrane potential/current or input resistance immediately before the application of the drug/ light and at the peak of the effect. A paired/unpaired $t$ test was used for statistical analysis of significance. Statistical analysis used SPSS software (release 11.5), and differences were considered significant at $p<0.05$.

\section{Results}

GABAergic neurons are intermingled with cholinergic neurons in the mouse $\mathrm{BF}$ and are surrounded by cholinergic fibers

As depicted in Figure 1, cholinergic and GABAergic neurons are in close proximity to each other in the BF. Immunohistochemical labeling for the acetylcholine synthesizing enzyme ChAT, in the $\mathrm{BF}$ of mice where GABAergic neurons are labeled with green fluorescent protein (GAD67-GFP knock-in mice; Tamamaki et al., 2003; McKenna et al., 2013), revealed that the distribution of cholinergic and GABAergic neurons overlapped. Quantification revealed that the highest density of $\mathrm{BF}$ cholinergic neurons was in the HDB $\left(97.6 \pm 17.1 \mathrm{ChAT}^{+}\right.$neurons $/ \mathrm{mm}^{2} /$ slice; $\left.n=4\right)$. Lower densities were found in the MCPO $\left(47.4 \pm 3.5 \mathrm{ChAT}^{+}\right.$neurons/ $\mathrm{mm}^{2} /$ slice) and dorsal BF nuclei (VP, $24.6 \pm 3.1 \mathrm{ChAT}^{+}$neurons $/ \mathrm{mm}^{2} /$ slice; SI, $20.0 \pm 1.3 \mathrm{ChAT}^{+}$neurons $/ \mathrm{mm}^{2} /$ slice). One-way ANOVA confirmed significant differences between the ChAT density of the four BF subnuclei $\left(F_{(3,12)}=16.035, p<\right.$ 0.001 ), and follow-up pairwise comparisons (Bonferroni cor-
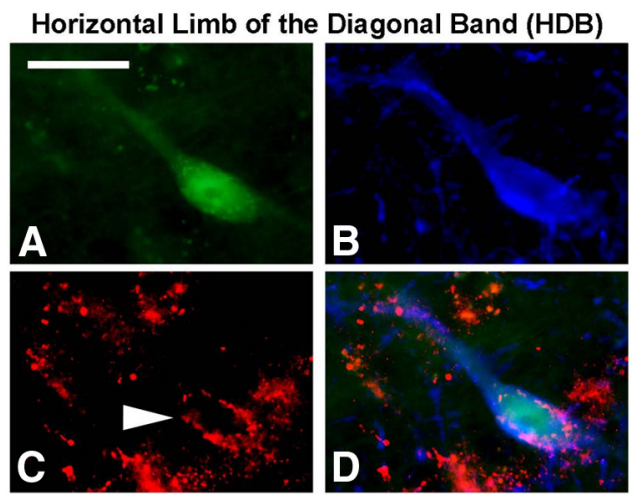

Magnocellular Preoptic Nucleus (MCPO)
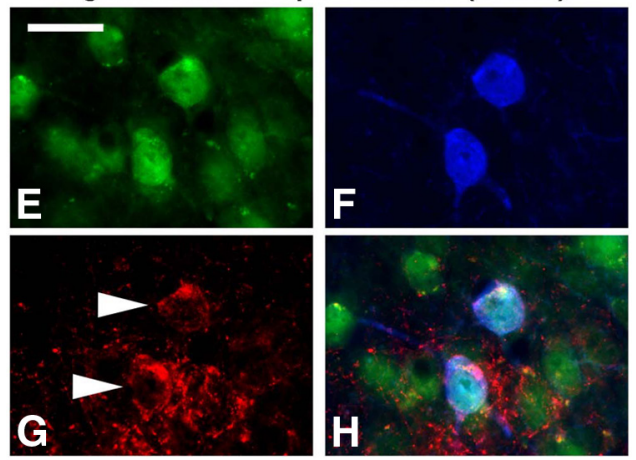

Figure 2. $\boldsymbol{A}-\boldsymbol{H}$, Cholinergic ( $\mathrm{VAChT}^{+}$) varicosities are closely apposed to $\mathrm{BF}$ GABAergic/PV neurons in the HDB $(\boldsymbol{A}-\boldsymbol{D})$ and the MCPO $(\boldsymbol{E}-\boldsymbol{H})$ of GAD67-GFP mice. Fluorescent images show $\mathrm{GFP}^{+}$(green, $\boldsymbol{A}$ and $\boldsymbol{E}$ ) and $\mathrm{PV}^{+}$(blue, $\boldsymbol{B}$ and $\boldsymbol{F}$ ) neurons. vAChT varicosities (red, $\boldsymbol{C}$ and $\boldsymbol{G}$ ) are apposed to $\mathrm{GABA}+/ \mathrm{PV}^{+}$neurons in both $\mathrm{BF}$ regions (merged images, $\boldsymbol{D}$ and $\boldsymbol{H}$, arrowheads). Punctate green fluorescence, perhaps suggestive of axon terminals, was also observed over the cell bodies of some $\mathrm{GFP}^{+}(\boldsymbol{E})$ and GFP ${ }^{-}$neurons $(\boldsymbol{A})$. Scale bars, $25 \mu \mathrm{m}$.

rected) revealed the following significant density differences: $\mathrm{HDB}>\mathrm{MCPO}(p=0.011)$; and HDB $>$ VP, SI $(p<0.001)$. Although the main cluster of cholinergic neurons was located more medially than the main cluster of large-sized $(>20 \mu \mathrm{m})$ GABAergic neurons, which we previously found were clustered in the MCPO (McKenna et al., 2013), $\mathrm{ChAT}^{+}$neurons were intermingled with large GABAergic $\left(\mathrm{GFP}^{+}\right)$neurons throughout the BF. In particular, cholinergic and large GABAergic neurons were closely intermingled in the lateral part of the $\mathrm{HDB}$ region and the medial part of the MCPO (Fig. 1). $\mathrm{ChAT}^{+}$neurons were not labeled with GFP, indicating that the GFP label is not expressed ectopically in cholinergic neurons (Fig. $1 D-F$ ).

To determine whether there are cholinergic synaptic varicosities in the vicinity of GABAergic BF neurons, and, in particular, cortically projecting $\left(\mathrm{PV}^{+}\right)$BF GABA neurons, we performed immunohistochemical staining for the vAChT and PV in brain tissue from GAD67-GFP mice. Multiple, punctate, $\mathrm{vAChT}^{+}{ }^{+}$varicosities were observed surrounding and apposed to $\mathrm{GFP}^{+} / \mathrm{PV}^{+}$ and $\mathrm{GFP}^{+} / \mathrm{PV}^{-}$neurons in both the $\mathrm{HDB}$ and $\mathrm{MCPO}$ (Fig. 2), as well as in other regions of the BF, suggesting innervation by cholinergic fibers.

\section{Pharmacological activation of cholinergic receptors excites BF GABAergic and $\mathrm{PV}^{+}$neurons}

To identify BF GABAergic neurons for electrophysiological recordings, we used GAD67-GFP knock-in mice (Tamamaki et al., 2003; McKenna et al., 2013). We focused our electrophysiological recordings on large $(>20 \mu \mathrm{m}) \mathrm{GFP}^{+}$neurons, which fired spontaneously at high rates and had a prominent depolarizing sag 


\section{Large Ih}

A
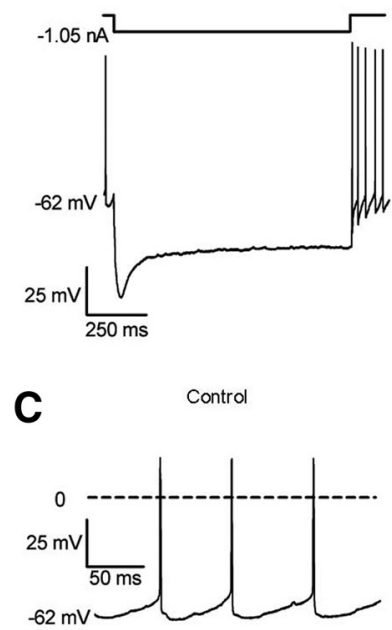

E

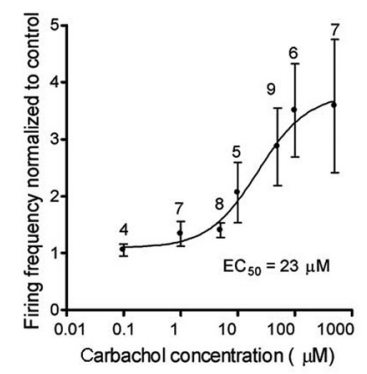

B

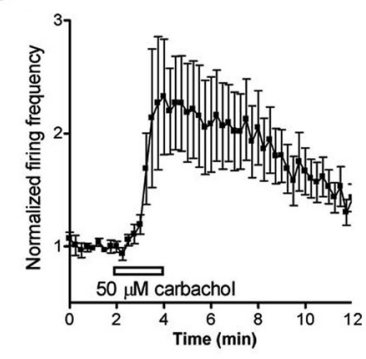

D

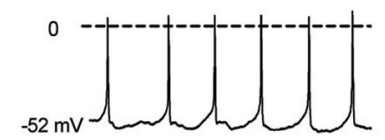

F

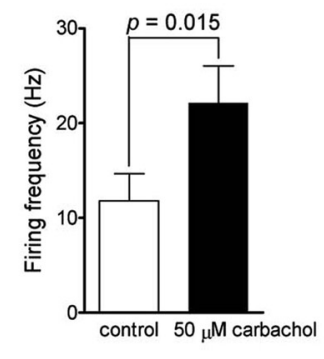

Small Ih
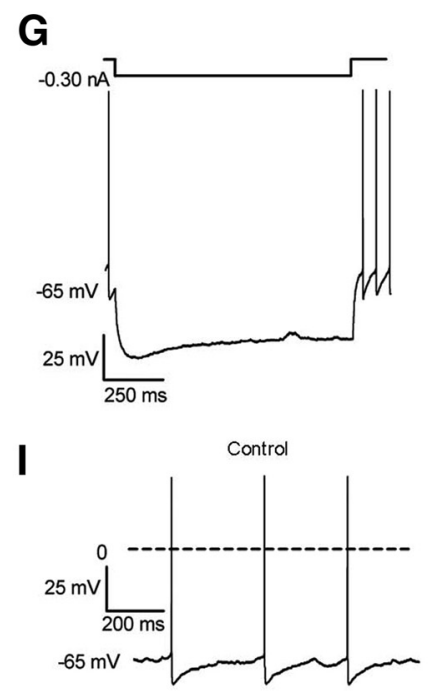

K

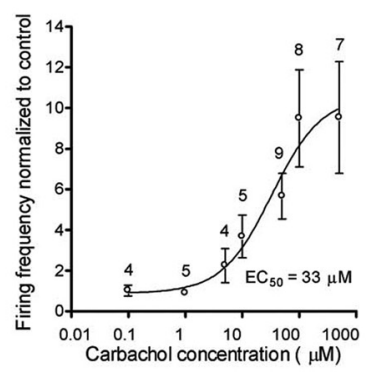

$\mathbf{H}$

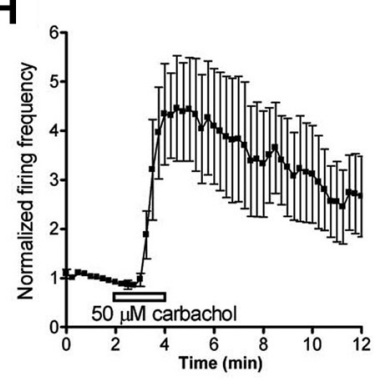

J

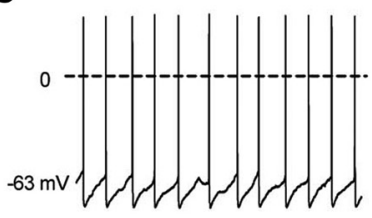

L

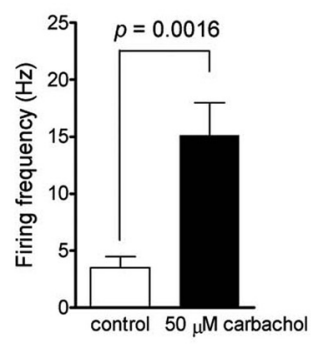

Figure 3. $\boldsymbol{A}-\boldsymbol{L}$, The cholinergic agonist carbachol excites two types of large $\mathrm{BF} G A B$ Aergic neurons, large $I_{\mathrm{h}}(\boldsymbol{A}-\boldsymbol{F})$ and $\operatorname{small} I_{\mathrm{h}}(\mathbf{G}-\boldsymbol{L}) \cdot \boldsymbol{A}, \mathrm{A} 1$ s hyperpolarizing current injection $(-1.05 \mathrm{nA})$ reveals a large depolarizing sag $(49.4 \%)$ with a biexponential decay $\left(\tau_{\text {fast }}=39.6 \mathrm{~ms}, \tau_{\text {slow }}=402.7 \mathrm{~ms}\right)$, defining this type of neuron. $B, A 50 \mu$ m dose of carbachol strongly increased the spontaneous firing frequency $(n=9) . C, D$, A representative recording from a large $I_{h}$ neuron showing the carbachol-induced depolarization andfiring. $\boldsymbol{E}$, Dose dependence of carbachol response. $\mathrm{EC}_{50}=23 \mu \mathrm{m}$. The number of neurons for each concentration of carbachol is given above each data point $(n=4-9) . F$, Mean data for the effect of $50 \mu \mathrm{m}$ carbachol on the firing frequency of large $I_{h}$ neurons. Control data were taken from the time point 2 min before application, whereas the carbachol response data were taken from the 5 min time point. Significance was assessed with a paired $t$ test. $\mathbf{G}, A 1 \mathrm{~s}$ hyperpolarizing current injection $(-0.30 \mathrm{nA})$ reveals a small depolarizing sag $(27.6 \%)$ with a monoexponential decay $(\tau=273.0 \mathrm{~ms})$, defining this type of neuron. $\boldsymbol{H}$, Time course of carbachol effect on action potential firing $(n=9)$. $\boldsymbol{I}, \boldsymbol{J}$, A representative recording from a large $I_{\mathrm{h}}$ neuron showing the carbachol-induced depolarization and firing. $\boldsymbol{K}$, Dose dependence of carbachol response. $\mathrm{EC}_{50}=33 \mu \mathrm{m}$. The number of neurons for each concentration of carbachol is given above each data point $(n=4-9)$. $L$, Mean data for the effect of $50 \mu \mathrm{m}$ carbachol on the firing frequency of $s m a l l l / \mathrm{h}$ neurons.

during hyperpolarizing current pulses. These neurons had the same size (Gritti et al., 2003) and intrinsic membrane properties as those identified in cortically projecting GABAergic neurons (McKenna et al., 2013). As in our previous study (McKenna et al., 2013), we subdivided these neurons into two groups based on the amplitude and kinetics of the depolarizing sag during hyperpolarizing current pulses. Since this sag was blocked by pharmacological blockers of the H-current (McKenna et al., 2013), we termed these subgroups large hyperpolarization-activated cation current $\left(I_{\mathrm{h}}\right)$ and small $I_{\mathrm{h}}$.

A brief ( $2 \mathrm{~min}$ ) bath application of the broad-spectrum cholinergic agonist carbachol $(50 \mu \mathrm{M})$ increased the firing rate of both large $I_{\mathrm{h}}$ and small $I_{\mathrm{h}}$ GABAergic neurons (Fig. 3; large $I_{\mathrm{h}}$ neurons: $11.8 \pm$ 2.9 to $22.1 \pm 3.9 \mathrm{~Hz}, p=0.015, n=9$; small $I_{\mathrm{h}}$ neurons: $3.5 \pm 0.9$ to $15.1 \pm 2.8 \mathrm{~Hz}, p=0.0016, n=9)$. This response was dose dependent with an $\mathrm{EC}_{50}$ value of $23 \mu \mathrm{M}$ in large $I_{\mathrm{h}}$ neurons and $33 \mu \mathrm{M}$ in small $I_{\mathrm{h}}$ neurons (Fig. 3). Carbachol also reduced spike amplitude, likely due to increased inactivation of voltage-gated sodium channels at depolarized membrane potentials (Fig. 3D).

An important subset of the cortically projecting BF GABAergic projection contains PV (Gritti et al., 2003), comprising 25\% of the large GABAergic neurons in the ventral BF (McKenna et al., 2013). To confirm that the cortically projecting $\mathrm{PV}^{+}$subpopulation is also excited, we recorded from $\mathrm{PV}^{+}$neurons in slices prepared from mice selectively expressing a red fluorescent marker in PV neurons (McKenna et al., 2013). Indeed, six of eight $\mathrm{PV}^{+}$neurons recorded in slices prepared from $P V$-tdTomato mice were excited by carbachol $(50 \mu \mathrm{M})$.

\section{Carbachol increases the firing frequency of BF GABAergic neurons via activation of $M_{1} / M_{3}$ receptors}

The broad-spectrum muscarinic receptor antagonist atropine (5 $\mu \mathrm{M}$ ) completely blocked the carbachol-induced increase in firing frequency in both large and small $I_{\mathrm{h}}$ GABAergic neurons, without having an effect on its own (large $I_{\mathrm{h}}$ : control, $9.1 \pm 2.1 \mathrm{~Hz}$; atropine, $8.8 \pm 1.7 \mathrm{~Hz}$; atropine with carbachol, $8.2 \pm 1.6 \mathrm{~Hz}$; no significant differences, repeated-measures ANOVA with Bonferroni post hoc test, $n=6$; small $I_{\mathrm{h}}$ : control, $9.5 \pm 5.1 \mathrm{~Hz}$; atropine, $9.9 \pm 4.8 \mathrm{~Hz}$; atropine with carbachol, $7.6 \pm 3.4 \mathrm{~Hz}$; no significant differences, $n=6$ ). Thus, excitatory carbachol responses are mediated through muscarinic receptors, but there is no basal cholinergic tone in the slice.

We next tested more selective muscarinic antagonists. Excitatory muscarinic effects in other brain regions are mediated via $M_{1}$-type 

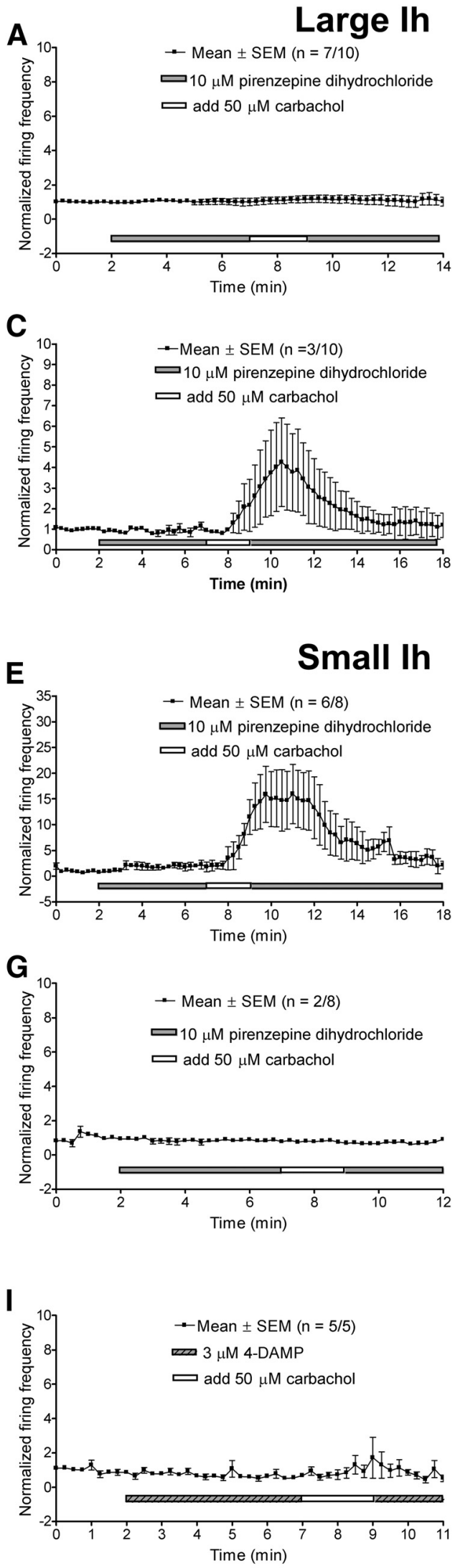

H
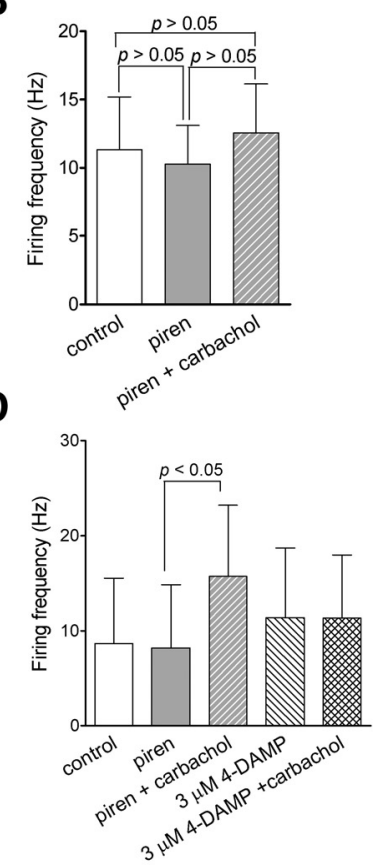

$\mathbf{F}$
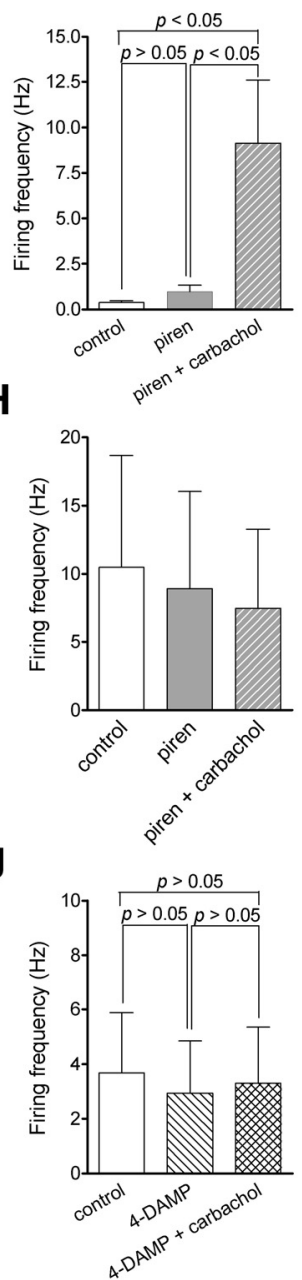

Figure 4. The excitatory effect of carbachol on BF GABAergic neurons is mediated by $M_{1} M_{3}$ receptors. $\boldsymbol{A}-\boldsymbol{J}$, The effect of carbachol is mainly mediated by the $M_{1}$ receptor in large $I_{h}$ GABAergic neurons $(\boldsymbol{A}-\boldsymbol{D})$ and by the $\mathrm{M}_{3}$ receptor in small $I_{\mathrm{h}} \mathrm{GABAergic}$ neurons $(\boldsymbol{E}-\boldsymbol{J})$. $\boldsymbol{A}$, Mean time course of carbachol response in the presence of an $M_{1}$ receptor antagonist, receptors $\left(M_{1}, M_{3}, M_{5}\right)$, whereas $M_{2}$-like receptors $\left(\mathrm{M}_{2}, \mathrm{M}_{4}\right)$ mediate inhibitory responses (Nicoll et al., 1990). Therefore, we focused on $\mathrm{M}_{1}$-type receptors, and in particular $M_{1}$ and $M_{3}$ receptors, since $M_{5}$ receptors appear to be at low levels or absent from BF (Allen Mouse Brain Atlas, http://mouse. brain-map.org). Although the effect of carbachol was blocked by atropine in both large $I_{\mathrm{h}}$ and small $I_{\mathrm{h}}$ neurons, there were differences between the two groups in their response to more specific muscarinic antagonists. In large $I_{\mathrm{h}}$ neurons, in the presence of the $M_{1}$ receptor antagonist pirenzepine dihydrochloride $(10 \mu \mathrm{M})$, the neuronal firing frequency $(9.6 \pm 2.6 \mathrm{~Hz})$ was similar to that before drug application $(10.5 \pm 3.2 \mathrm{~Hz}, p=0.45, n=10)$. Most of the neurons $(n=7 / 10)$ exposed to $10 \mu \mathrm{M}$ pirenzepine did not show any significant change in firing frequency when carbachol was applied (Fig. 4A; baseline, $10.3 \pm 2.9$ $\mathrm{Hz}$; in carbachol, $12.7 \pm 3.8 \mathrm{~Hz} ; t_{(20)}=1.83$; $p>0.05$, repeated-measures ANOVA with Bonferroni post hoc test, $n=7$ ). This inhibition was dose dependent. When the firing rate was normalized to that before carbachol application, the firing rate was increased by $2.87 \pm 0.68$-fold $(n=9), 3.03 \pm 0.63$-fold $(n=9), 1.72 \pm 0.26$-fold $(n=5)$, and $1.23 \pm 0.15$-fold $(n=7)$ in the presence of 0 , $0.1,1$, and $10 \mu \mathrm{M}$ pirenzepine, respectively. Three neurons still showed a significant increase in firing frequency from $8.2 \pm 6.6$ to $15.7 \pm 7.5 \mathrm{~Hz}$ in $10 \mu \mathrm{M}$ pirenzepine in response to carbachol stimulation (Fig. $4 C$; $p<0.05$, Friedman's test with Dunn's

\footnotetext{
pirenzepine dihydrochloride $(10 \mu \mathrm{M})$. The carbachol response was inhibited in seven of nine neurons. $\boldsymbol{B}$, Summary of the pirenzepine effect on carbachol response of the seven neurons shown in $A$. The firing frequency at three time points ( $2 \mathrm{~min}$ for control, 7 min for pirenzepine alone, and $10 \mathrm{~min}$ for pirenzepine with carbachol) were compared by one-way ANOVA with Bonferroni's multiple-comparison test. $\boldsymbol{C}$, Mean time course of carbachol response in the presence of pirenzepine for the remaining three neurons. The carbachol response was not blocked by pirenzepine in these neurons but was subsequently inhibited by incubation with an $M_{3}$ receptor antagonist, 4-DAMP $(3 \mu \mathrm{M})$, as shown in $\boldsymbol{D}$ summary data. $\boldsymbol{E}$, Mean time course of carbachol response in the presence of pirenzepine for small $I_{h}$ GABAergic neurons. The carbachol response was not blocked in six of eight neurons. $\boldsymbol{F}$, Summary of the pirenzepine effect on carbachol response for the six cells in $\boldsymbol{D}$. G, Mean time course of carbachol response in the presence of pirenzepine for the remaining two neurons. The carbachol response was completely blocked by pirenzepine in these neurons, as shown in $\boldsymbol{H}$ summary data. $I$, Mean time course of carbachol response in the presence of $3 \mu \mathrm{m} 4-D A M P$ for five neurons with small $I_{\mathrm{h}}$. The carbachol response was inhibited in all five cells. J, Mean data of the neurons recorded in $I$. The carbachol response in small $I_{h}$ neurons was significantly inhibited by the $M_{3}$ receptor antagonist.
} 
multiple-comparison test, $n=3$ ). After washing out carbachol and pirenzepine from the bath, these three neurons were incubated with an $\mathrm{M}_{3}$ receptor antagonist, 4-DAMP $(3 \mu \mathrm{M})$, for 5-8 min, and then the effect of carbachol was retested. Their firing frequency was similar in 4-DAMP, and there was no significant difference from that before carbachol application (Fig. $4 D$; control, $8.6 \pm 6.9 \mathrm{~Hz}$; 4-DAMP, $11.4 \pm 7.3 \mathrm{~Hz} ; p>0.05$, Friedman's test with Dunn's multiple-comparison test, $n=3$ ). In control experiments without any antagonist, carbachol induced a consistent and repeatable increase in firing during the second application (control, $6.2 \pm 2.1 \mathrm{~Hz}$; first carbachol application, $22.3 \pm 6.7 \mathrm{~Hz}$; washout, $5.1 \pm 1.6 \mathrm{~Hz}$; second carbachol application, $17.0 \pm 6.1 \mathrm{~Hz}$; there were no significant differences in the firing frequencies at baseline or in the presence of carbachol; control vs washout, $p=0.6289$; first vs second carbachol application, $p=0.205$, paired $t$ test). These data suggest that the response to carbachol in the majority of large $I_{\mathrm{h}}$ GABAergic neurons is mediated via $M_{1}$ receptors, and in a smaller population via $M_{3}$ receptors.

In small $I_{\mathrm{h}}$ neurons, the effects of $\mathrm{M}_{1}$ and $\mathrm{M}_{3}$ receptorselective antagonists were reversed. The carbachol effect on firing frequency persisted in most small $I_{\mathrm{h}}$ neurons (six of eight neurons) with a $5 \mathrm{~min}$ incubation in $10 \mu \mathrm{M}$ of the $\mathrm{M}_{1}$ receptor antagonist pirenzepine (Fig. $4 E, F$ ). Their firing frequencies in regular ACSF, pirenzepine, and carbachol with pirenzepine were respectively $0.37 \pm 0.12,0.96 \pm 0.37$, and $9.13 \pm 3.48 \mathrm{~Hz}$ (ACSF vs pirenzepine, $p>0.05$; pirenzepine with carbachol vs ACSF/ pirenzepine; $p<0.05$, repeated-measures ANOVA with Bonferroni post-test, $n=6 / 8$ ). The remaining two neurons did not respond to carbachol in the presence of $10 \mu \mathrm{M}$ pirenzepine (control, $10.5 \pm 8.2 \mathrm{~Hz}$; pirenzepine, $8.9 \pm 7.1 \mathrm{~Hz}$; pirenzepine plus carbachol, $7.4 \pm 5.8 \mathrm{~Hz}$; Fig. $4 G$ ). In contrast to the effect of pirenzepine in large $I_{\mathrm{h}}$ neurons, increases in firing rate in response to carbachol were observed even in the presence of pirenzepine, even at concentrations as high as $50 \mu \mathrm{M}$, although at the highest dose $(50 \mu \mathrm{M})$ there was a trend-level $(p=0.12)$ reduction in the increase in firing produced by carbachol. When the firing rate was normalized to that before carbachol application, the firing rate was significantly increased by $5.67 \pm 1.12$-fold $(n=9)$, $7.72 \pm 3.04$-fold $(n=5), 5.84 \pm 3.62$-fold $(n=8)$, and $3.2 \pm$ 0.86 -fold $(n=6)$ in the presence of $0,0.1,10$, and $50 \mu \mathrm{M}$ pirenzepine, respectively. In contrast, in all small $I_{\mathrm{h}}$ neurons tested $(n=5)$, 4-DAMP completely blocked the carbachol response (Fig. 4I). The firing frequencies in ACSF, $3 \mu \mathrm{M} 4$-DAMP, and 4-DAMP with carbachol were, respectively, $3.68 \pm 2.20,2.95 \pm$ 1.90 , and $3.31 \pm 2.05 \mathrm{~Hz}(p>0.05$, repeated-measures ANOVA with Bonferroni post-test, $n=5)$. The normalized increase in firing induced by carbachol was inhibited by 4-DAMP with a steep dose dependence, as follows: $5.67 \pm 1.12$-fold increase without 4-DAMP $(n=9)$; $7.1 \pm 2.8$ with $0.3 \mu \mathrm{M} 4$-DAMP; $5.5 \pm$ 2.7 with $1 \mu \mathrm{M} 4$-DAMP $(n=4)$; and $1.3 \pm 0.18$ with $3 \mu \mathrm{M}$ 4-DAMP $(n=5)$; that is, doses of 0.3 and $1 \mu \mathrm{M}$ did not block the effect of carbachol, but a dose of $3 \mu \mathrm{M}$ caused a complete block. These results suggest that the $\mathrm{M}_{3}$ receptor mediates the carbachol response in most small $I_{\mathrm{h}}$ GABAergic neurons.

\section{Bath-applied carbachol-induced inward currents in GABAergic neurons via muscarinic receptors and opening sodium-permeable cation channels}

Carbachol depolarized both large and small $I_{\mathrm{h}}$ neurons (large $I_{\mathrm{h}}$, $8.1 \pm 1.1 \mathrm{mV}$; small $I_{\mathrm{h}}, 11.3 \pm 1.6 \mathrm{mV}$ ) in the presence of TTX $(0.5 \mu \mathrm{M})$, suggesting a direct postsynaptic effect. Under voltageclamp at a holding potential of $-60 \mathrm{mV}$, carbachol-induced inward currents of $-171 \pm 44 \mathrm{pA}$ (baseline current changed from
$-190 \pm 55.8$ to $-363.6 \pm 68.0 \mathrm{pA} ; p=0.0036$, paired $t$ test $)$ and $-52 \pm 14 \mathrm{pA}$ (baseline current changed from $-113.2 \pm 27.1$ to $-164.8 \pm 39.8 \mathrm{pA} ; p=0.0088$, paired $t$ test $)$ in large $(n=11)$ and small $I_{\mathrm{h}}(n=8)$ neurons, respectively (Fig. 5$)$. In both types of neurons, the inward current was accompanied by an increase in membrane current noise [large $I_{\mathrm{h}}$ : root mean square (RMS) of baseline, $4.8 \pm 0.7 \mathrm{pA}$; vs carbachol, $13 \pm 3.0 \mathrm{pA} ; p=0.0257$, paired $t$ test, $n=11$; small $I_{\mathrm{h}}$ : RMS baseline, $4.0 \pm 0.7 \mathrm{pA}$; vs carbachol, $6.2 \pm 1.2 \mathrm{pA} ; p=0.0130$, paired $t$ test, $n=8$ ], suggesting that more channels are opening and closing in the presence of carbachol. In the presence of atropine, carbachol did not induce any significant change in baseline current for either large $I_{\mathrm{h}}$ neurons $(n=5)$ or small $I_{\mathrm{h}}$ neurons $\left(n=6\right.$; large $I_{\mathrm{h}}$ holding current in atropine vs atropine plus carbachol: $-166.5 \pm 56.3$ vs $-166.0 \pm 56.9 \mathrm{pA}, p=0.7686$; small $I_{\mathrm{h}}$ holding current in atropine vs atropine plus carbachol: $-69.2 \pm 21.2$ vs $-76.5 \pm 17.4$ pA, $p=0.2730$; paired $t$ test), suggesting that the postsynaptic current response was mediated via muscarinic receptors.

To test whether the carbachol-induced inward current reverses at the equilibrium potential for potassium ions $(-100$ $\mathrm{mV}$ under our conditions), we applied slow (4 s) voltage ramps from -120 to $-60 \mathrm{mV}$ every $30 \mathrm{~s}$ and compared the response in baseline from that in carbachol. However, these responses did not cross in any of the neurons tested. In most large $I_{\mathrm{h}}$ neurons ( 7 of 10) and small $I_{\mathrm{h}}$ neurons (6 of 8 ), the current difference between carbachol application and control converged as the voltage became less negative, suggesting a reversal at more positive potentials. In the remaining neurons, the curves remained parallel in this voltage range. Thus, a decrease in leak potassium conductance is not the major mediator of the carbachol excitation.

To test whether the carbachol-induced inward current is due to the opening of mixed cation channels, which normally have a reversal potential $\sim 0 \mathrm{mV}$, we applied ramps from -100 to 40 $\mathrm{mV}$. To remove the influence of calcium spikes and voltage-gated $\mathrm{Na}^{+}$channels, we used a calcium-free extracellular solution containing TTX $(0.5 \mu \mathrm{M})$. The amplitude of the carbachol-induced inward current under these conditions (large $I_{\mathrm{h}}: 82.3 \pm 15.2 \mathrm{pA}$, $n=10$; small $I_{\mathrm{h}}$ : $99.6 \pm 16.1 \mathrm{pA}, n=14$ ) was not significantly different from that in regular ACSF ( $p>0.05$, unpaired $t$ test). In 9 of 13 large $I_{\mathrm{h}}$ neurons and 7 of 14 small $I_{\mathrm{h}}$ neurons tested with this protocol, the carbachol-induced inward current reversed close to $0 \mathrm{mV}$ (Fig. 5 ; large $I_{\mathrm{h}}: 0.6 \pm 5.4 \mathrm{mV}, n=9$ : small $I_{\mathrm{h}}: 4.4 \pm$ $8.5 \mathrm{mV}, n=7)$. In three large $I_{\mathrm{h}}$ neurons and five small $I_{\mathrm{h}}$ neurons, there was no reversal in the range from -100 to $40 \mathrm{mV}$. One large $I_{\mathrm{h}}$ neuron and two small $I_{\mathrm{h}}$ neurons showed outward currents from -100 to $-75 \mathrm{mV}$, but inward currents from -75 to 40 $\mathrm{mV}$. These data indicated that in most neurons, carbachol opened mixed cation channels permeable to both $\mathrm{Na}^{+}$and $\mathrm{K}^{+}$. However, closure of leak potassium channels may also be involved in some neurons.

If $\mathrm{Na}^{+}$is the main ion carrying the carbachol-induced inward current in most neurons, removing extracellular $\mathrm{Na}^{+}$ should strongly reduce the carbachol-induced inward current. To test this hypothesis, we reduced the extracellular $\mathrm{Na}^{+}$concentration from 152.6 to $25.6 \mathrm{~mm}$ by replacing $\mathrm{NaCl}$ by equimolar NMDG chloride. Switching the bath solution from ACSF to the low- $\mathrm{Na}^{+} /$calcium-free/TTX-containing solution induced outward currents in both large $I_{\mathrm{h}}(149.4 \pm 35.1 \mathrm{pA}$, $n=9)$ and small $I_{\mathrm{h}}(63.0 \pm 7.9 \mathrm{pA}, n=15)$ neurons, likely due to a reduction in hyperpolarization-activated cation currents active at the holding potential $(-60 \mathrm{mV}$; McKenna et al., 2013). In both large and small $I_{\mathrm{h}}$ neurons, the carbachol- 
A

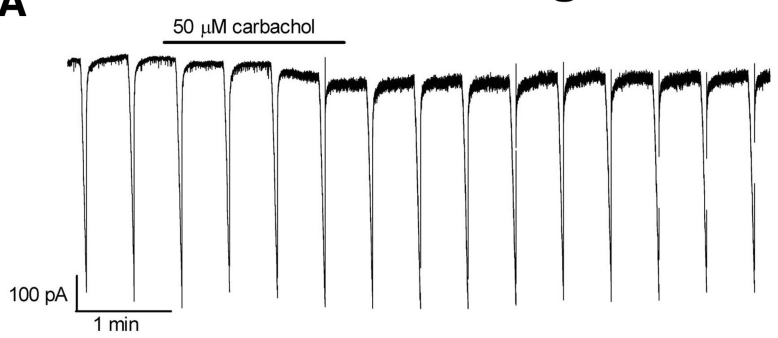

C

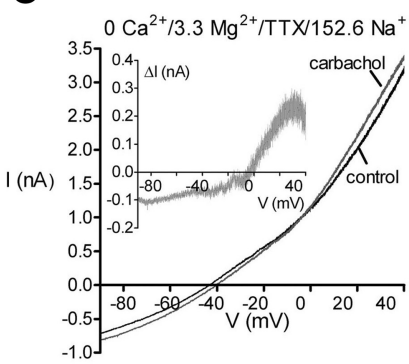

D

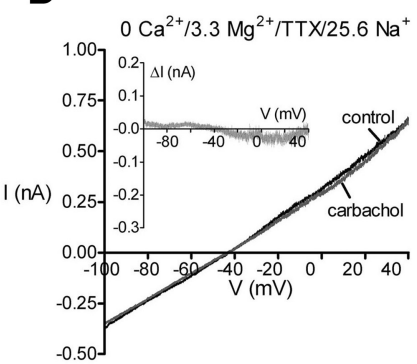

\section{Small Ih}

F
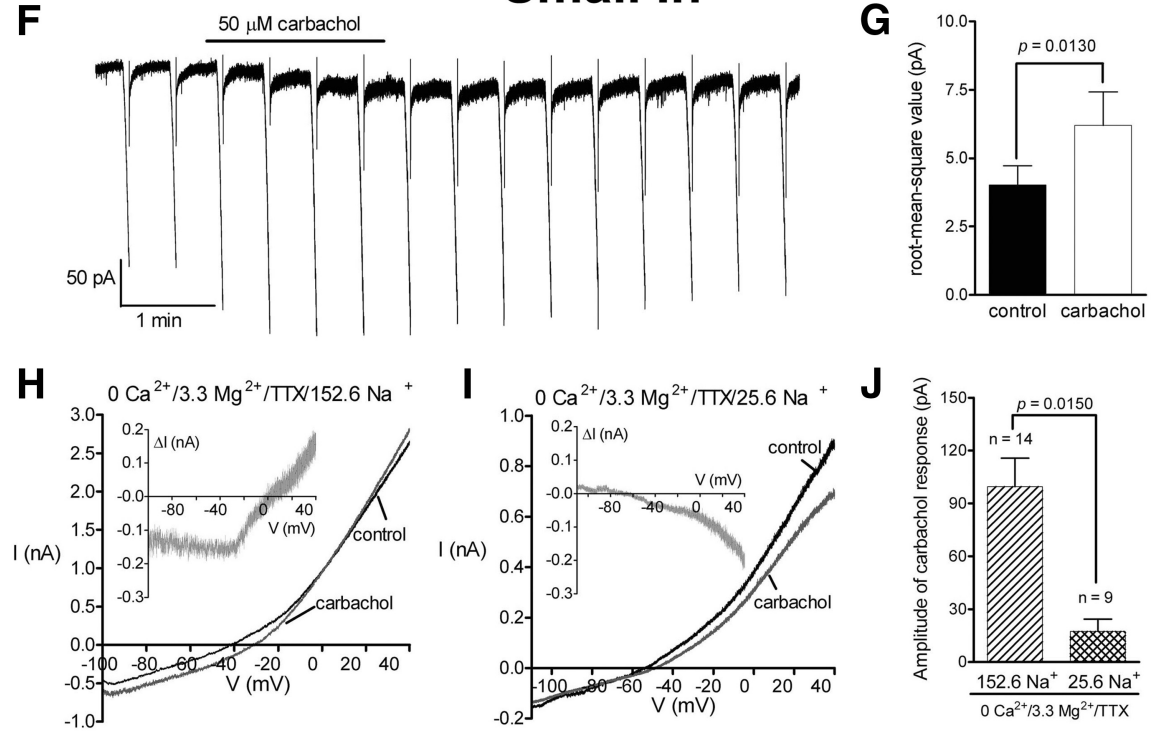

Figure 5. Carbachol activates a noisy, sodium-permeable cation current in BF GABAergic neurons. Large $I_{\mathrm{h}}$ neurons are shown in $\boldsymbol{A}-\boldsymbol{E}$. Small $I_{\mathrm{h}}$ neurons are shown in $\boldsymbol{F}$-J. $\boldsymbol{A}$, Carbachol induces an inward current at $-60 \mathrm{mV}$ in large $I_{\mathrm{h}}$ neurons. Downward deflections are voltage ramps from -120 to $-60 \mathrm{mV}$. No reversal was seen in this voltage range. $\boldsymbol{B}$, Carbachol significantly increases membrane current noise. $C$, The carbachol-induced current reverses at $\sim 0 \mathrm{mV}$ in regular extracellular $\left[\mathrm{Na}^{+}\right](152.6 \mathrm{~mm})$. $D$, The reversal potential of the carbachol-induced current shifts in the negative direction when extracellular $\mathrm{Na}^{+}$is decreased. Insets in $\boldsymbol{C}$ and $\boldsymbol{D}$ show current-voltage relationships obtained by subtracting the control response from the response in the presence of carbachol. $\boldsymbol{E}$, Decreasing extracellular sodium significantly reduces the amplitude of the carbachol-induced current measured at $-60 \mathrm{mV}$. F, Carbachol induces an inward current at $-60 \mathrm{mV}$ in small $\mathrm{h}_{\mathrm{h}}$ neurons. Downward deflections are voltage ramps from -120 to $-60 \mathrm{mV}$. No reversal was seen in this voltage range. $\mathbf{G}$, Carbachol significantly increases membrane current noise in small $I_{\mathrm{h}}$ GABAergic neurons. $\boldsymbol{H}$, The carbachol-induced current reverses at $\sim 0 \mathrm{mV}$ in regular extracellular $\left[\mathrm{Na}^{+}\right](152.6$ mм). $I$, The reversal potential of the carbachol-induced current shifts in the negative direction when extracellular $\mathrm{Na}^{+}$is decreased. Insets in $\boldsymbol{H}$ and $\boldsymbol{I}$ show current-voltage relationships obtained by subtracting the control response from the response in the presence of carbachol. J, Decreasing extracellular sodium significantly reduces the amplitude of the carbachol-induced current measured at $-60 \mathrm{mV}$.

induced inward current in low- $\mathrm{Na}^{+} /$calcium-free ACSF was significantly smaller than that in regular $\mathrm{Na}^{+} /$calcium-free solution (Fig. 5; large $I_{\mathrm{h}}$ : $-11.1 \pm 9.2 \mathrm{pA} ; n=8 ; p=0.0017$, unpaired $t$ test; small $I_{\mathrm{h}}:-17.4 \pm 6.9 \mathrm{pA} ; n=9 ; p=0.0008$, unpaired $t$ test). Furthermore, the reversal potentials were significantly more negative (large $I_{\mathrm{h}}:-56.6 \pm 6.0 \mathrm{mV} ; n=8$; $p<0.01$, unpaired $t$ test; small $I_{\mathrm{h}}$ : $-71.4 \pm 2.0 \mathrm{mV} ; n=5 / 7 ; p<0.01$, unpaired $t$ test) than in normal $\mathrm{Na}$ ACSF. Thus, both reversal potential measurements and sodium-substitution experiments suggested that the inward current is mediated by sodium-permeable cation channels.

\section{Carbachol increases the frequency of synaptic inputs to GABAergic neurons} Finally, we investigated the effect of carbachol on the synaptic inputs to BF GABAergic neurons. Spontaneous EPSCs (sEPSCs) were recorded at a holding potential of -60 $\mathrm{mV}$ in the presence of $10 \mu \mathrm{M}$ GABAzine to block $\mathrm{GABA}_{\mathrm{A}}$ receptor-mediated events. In both large $I_{\mathrm{h}}$ and small $I_{\mathrm{h}}$ neurons, carbachol caused a large increase in the sEPSC frequency (Fig. 6; large $I_{\mathrm{h}}$ : control, $5.7 \pm 1.9$ $\mathrm{Hz}$; vs carbachol, $11.6 \pm 3.2 \mathrm{~Hz} ; p=0.028$, paired $t$ test; $n=6$; small $I_{\mathrm{h}}$ : control, $1.9 \pm$ $0.8 \mathrm{~Hz}$; vs carbachol, $4.7 \pm 1.1 \mathrm{~Hz} ; p=$ 0.0267; paired $t$ test; $n=10)$ and a smaller increase in the sEPSC amplitude (large $I_{\mathrm{h}}$ : control, $-18.0 \pm 0.9 \mathrm{pA}$; vs carbachol, $-25.2 \pm 3.3 \mathrm{pA} ; p=0.0469$, paired $t$ test; $n=6$; small $I_{\mathrm{h}}$ : control, $-16.6 \pm 1.7 \mathrm{pA}$; vs carbachol, $-21.0 \pm 3.3 \mathrm{pA} ; p=0.0406$, paired $t$ test; $n=10$ ), suggesting that carbachol causes both presynaptic and postsynaptic changes. Carbachol did not cause a significant change in the frequency or amplitude of miniature EPSCs (mEPSCs) recorded in the presence of TTX $(0.5 \mu \mathrm{M})$ in large $I_{\mathrm{h}}$ GABAergic neurons. The frequency and amplitude of mEPSCs for large $I_{\mathrm{h}}$ GABAergic neurons were $2.90 \pm 0.95 \mathrm{~Hz}$ and $-18.2 \pm 1.5 \mathrm{pA}$ in control, and $1.91 \pm$ $0.72 \mathrm{~Hz}$ and $-19.9 \pm 1.3 \mathrm{pA}$ in carbachol ( $p=0.1788$ for frequency; $p=0.1290$ for amplitude, paired $t$ test; $n=4$ ). Thus, carbachol likely increased the frequency of sEPSCs by increasing the excitability of local glutamatergic neurons synapsing on the recorded neuron. For small $I_{\mathrm{h}}$ GABAergic neurons, there was a small but significant decrease in the frequency of mEPSCs with carbachol application (mEPSC frequency: control, $2.87 \pm 0.51 \mathrm{~Hz}$; vs carbachol, $1.33 \pm 0.34 \mathrm{~Hz} ; p=0.0106$; mEPSC amplitude: control, $-17.6 \pm 0.9 \mathrm{pA}$; vs carbachol, $-20.5 \pm 1.9 \mathrm{pA} ; p>0.05 ; n=6)$. Thus, as with large $I_{\mathrm{h}}$ neurons, increases in the frequency of sEPSCs by carbachol were due to increased excitability of local glutamatergic neurons.

Carbachol had similar effects on inhibitory synaptic inputs. Spontaneous IPSCs (sIPSCs) were recorded at a holding potential of $-90 \mathrm{mV}$ using a $\mathrm{KCl}$-based patch solution to increase the driving force for chloride entry in the presence of glutamate receptor antagonists. In both large and small $I_{\mathrm{h}}$ neurons, carbachol significantly increased the frequency and am- 
plitude of sIPSCs (Fig. 7; large $I_{\mathrm{h}}$ neurons: sIPSC frequency: control, $13.3 \pm 5.9 \mathrm{~Hz}$; vs carbachol, $28.5 \pm 7.1 \mathrm{~Hz} ; p=0.0028$; sIPSC amplitude: control, $-31.6 \pm 7.5$ pA; vs carbachol, $-43.5 \pm 10.1 \mathrm{pA} ; p=$ $0.0484 ; n=7$; small $I_{\mathrm{h}}$ neurons: sIPSC frequency: control, $6.2 \pm 2.0 \mathrm{~Hz}$; vs carbachol, $27.6 \pm 7.9 \mathrm{~Hz} ; p=0.0201$; sIPSC amplitude: control, $-33.1 \pm 8.0 \mathrm{pA}$; vs carbachol, $-57.9 \pm 16.0 \mathrm{pA} ; p=0.0410$; $n=6)$. There was no significant change in the frequency or amplitude of miniature IPSCs (mIPSCs) in large or small $I_{\mathrm{h}}$ GABAergic neurons (large $I_{\mathrm{h}}$ neurons: mIPSC frequency: control, $4.3 \pm 2.6 \mathrm{~Hz}$; vs carbachol, $3.3 \pm 0.7 \mathrm{~Hz} ; p=0.6616$; mIPSC amplitude: control, $-23.3 \pm 3.1$ pA; vs carbachol, $-25.6 \pm 3.6 \mathrm{pA} ; p=$ $0.5772 ; n=5$; small $I_{\mathrm{h}}$ neurons: mIPSC frequency: control, $2.6 \pm 1.0 \mathrm{~Hz}$; vs carbachol, $1.5 \pm 0.5 \mathrm{~Hz} ; p=0.0786$; mIPSC amplitude: control, $-26.0 \pm 3.2 \mathrm{pA}$; vs carbachol, $-31.8 \pm 5.9 \mathrm{pA} ; p=0.2405$; $n=6)$. Thus, in both large and small $I_{\mathrm{h}}$ neurons, increases in sIPSC frequency were likely to be due to increased excitability of local GABAergic neurons.

\section{Optical stimulation of cholinergic neurons in ChAT-ChR2-EYFP mice causes an inward current in putative GABAergic/PV neurons}

Our results presented above reveal strong pharmacological evidence for cholinergic effects on BF GABAergic neurons. Next, we investigated whether BF GABAergic neurons are excited by acetylcholine released from cholinergic neurons. We used mice in which a ChR2 and EYFP fusion protein is constitutively expressed under the control of the ChAT promoter (Zhao et al., 2011). Immunohistochemical staining for ChAT in ChAT-ChR2-EYFP mice confirmed that $87.3 \pm 2.2 \%$ of $\mathrm{EYFP}^{+}$ neurons stained positively for ChAT, while $90.2 \%$ of $\mathrm{ChAT}^{+}$neurons were $\mathrm{EYFP}^{+}(n=4$; Fig. $8 A-C)$. Thus, ChR2EYFP was expressed selectively in cholinergic neurons, and almost all cholinergic neurons expressed ChR2-EYFP.

To verify that light could stimulate action potentials in cholinergic neurons in BF slices prepared from ChAT-ChR2-EYFP mice, we first recorded the response of $\mathrm{EYFP}^{+}$neurons to blue $(470 \mathrm{~nm})$ light stimulation. As expected, EYFP ${ }^{+}$neurons were large neurons (long-axis diameter, 21.6 $\pm 1.0 \mu \mathrm{m} ; n=9$ ), which had the typical intrinsic membrane properties of $\mathrm{ChAT}^{+}$cholinergic neurons (McKenna et al., 2013; Fig. 8D), including a low maximal firing frequency $(15.3 \pm 3.2 \mathrm{~Hz} ; n=4)$ and large afterhyperpolarizations $(-22.6 \pm 3.4 \mathrm{mV} ; n=9)$. All EYFP ${ }^{+}$neurons tested responded to $470 \mathrm{~nm}$ light with action potentials confirming the excitatory function of these channels $(n=8$; Fig. $8 D-G)$. When stimulated at $10 \mathrm{~Hz}$ for $10 \mathrm{~s}$ ( $10 \mathrm{~ms}$ pulse width), $78 \pm 21 \%$ of light pulses elicited action potentials. Thus, optical
Large Ih

A

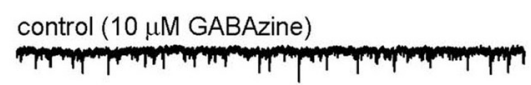

+ carbachol

$+20 \mu \mathrm{M} \mathrm{DNQX}+50 \mu \mathrm{M}$ AP5

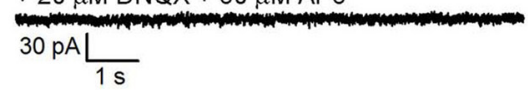

B
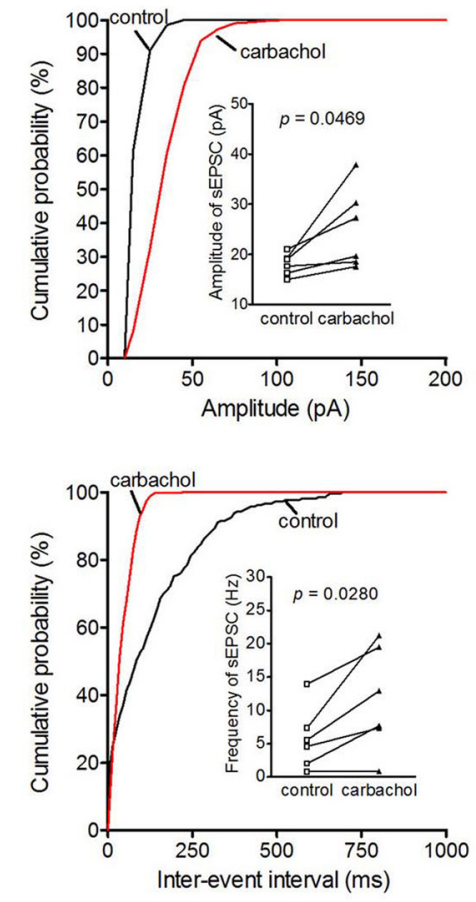

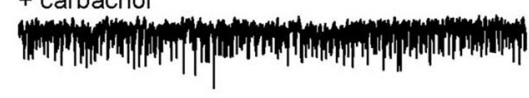

Small Ih

D

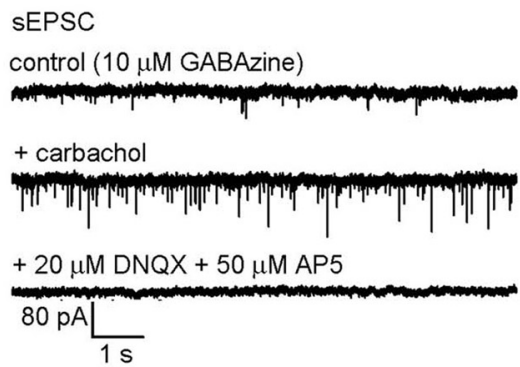

$\mathbf{E}$

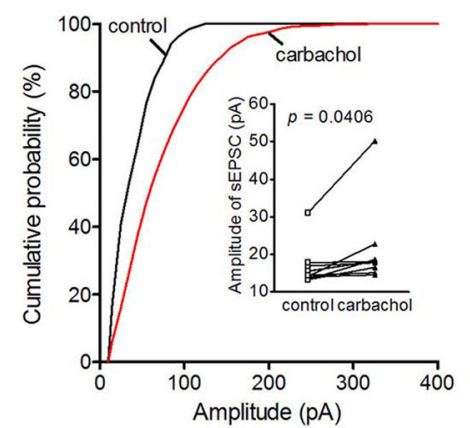

$\mathbf{F}$

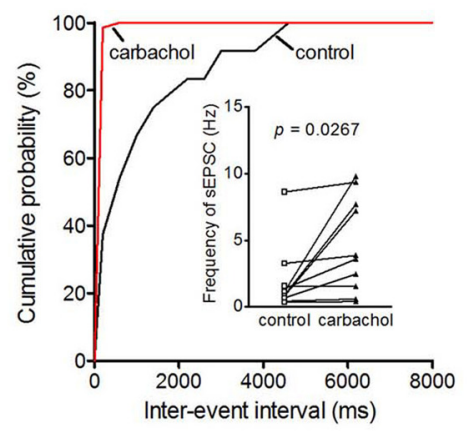

Figure 6. $\boldsymbol{A}-\boldsymbol{F}$, Carbachol increases the frequency and amplitude of $s E P S C s$ in both large $I_{\mathrm{h}}(\boldsymbol{A}-\boldsymbol{C})$ and small $I_{\mathrm{h}}(\boldsymbol{B}-\boldsymbol{F}) \mathrm{BF}$ GABAergic neurons. The holding potential was $-60 \mathrm{mV}$. Experiments were conducted in the presence of the GABA receptor antagonist GABAzine to isolate excitatory events. $\boldsymbol{A}, \boldsymbol{D}$, Representative raw $10 \mathrm{~s}$ data traces in control (top) and in the presence of plitude. sEPSCs were completely blocked (bottom trace) by a mixture of glutamatergic receptor antagonists (AMPA/kainate I lmogorov-Smirnov two-sample test). $\boldsymbol{C}, \boldsymbol{F}$, The cumulative probability histograms for interevent intervals of sEPSCs show

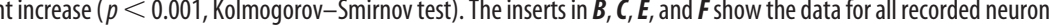
(large $I_{h}, n=6 ;$ small $I_{h}, n=10$ ). In both groups, there was a statistically significant increase in the frequency and amplitude of $\operatorname{sEPSCS}(p<0.05$, paired $t$ test $)$

stimulation is very effective in eliciting action potentials in cholinergic neurons.

To test whether the stimulation of cholinergic neurons/fibers causes postsynaptic responses in GABAergic neurons, we recorded light-induced responses from large-sized $(21.5 \pm 0.6 \mu \mathrm{m}$ long-axis diameter), EYFP-negative neurons $(n=32)$, which showed intrinsic membrane properties similar to those of identified cortical projecting GABAergic neurons (McKenna et al., 2013; Fig. $8 H$; large $I_{\mathrm{h}}, n=13$ : depolarizing sag, $56.1 \pm 1.9 \%$; $\mathrm{RMP},-63.9 \pm 1.8 \mathrm{mV}$; input resistance, $111.5 \pm 17.2 \mathrm{M} \Omega$; spontaneous firing frequency, $13.2 \pm 2.9 \mathrm{~Hz}$; small $I_{\mathrm{h}}, n=19$ : depolarizing sag, $29.4 \pm 2.6 \%$; RMP, $-62.6 \pm 1.2 \mathrm{mV}$; input resistance, $197.6 \pm 29.6 \mathrm{M} \Omega$; spontaneous firing frequency, $8.9 \pm$ 


\section{Large Ih}

A

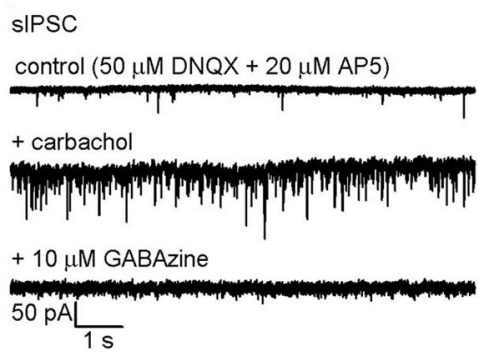

B

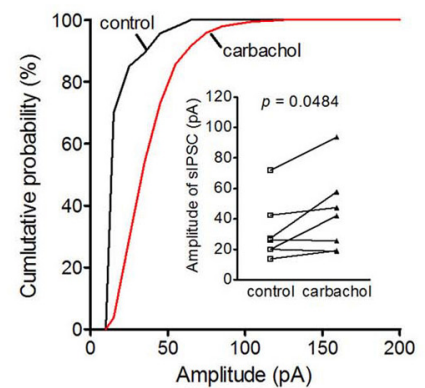

C

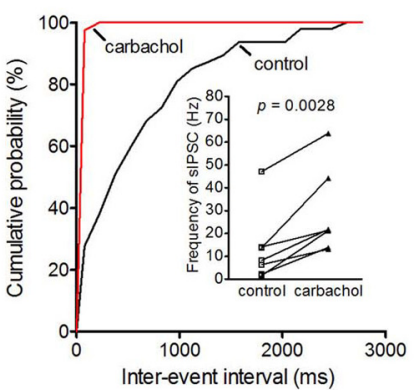

Small Ih

D

sIPSC

control (50 $\mu \mathrm{M}$ DNQX + $20 \mu \mathrm{M}$ AP5)

"

+ carbachol

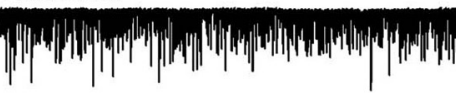

$+10 \mu \mathrm{M}$ GABAzine

$80 \mathrm{pAL}$

E

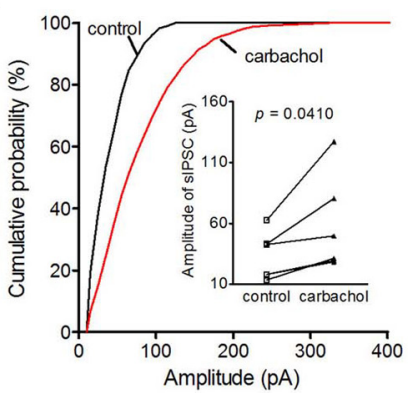

$\mathbf{F}$

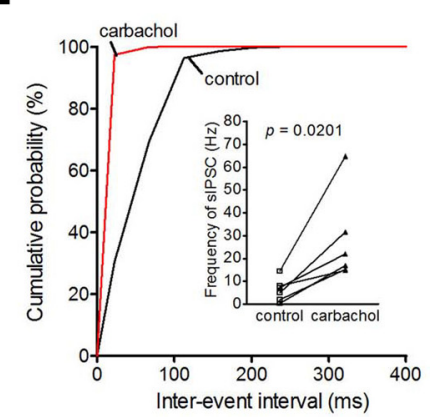

Figure 7. $\boldsymbol{A}-\boldsymbol{F}$, Carbachol increases the frequency and amplitude of sIPSCs in both large $I_{\mathrm{h}}(\boldsymbol{A}-\boldsymbol{C})$ and small $I_{\mathrm{h}}(\boldsymbol{D}-\boldsymbol{F}) \mathrm{BF}$ GABAergic neurons. The holding potential was $-90 \mathrm{mV}$. Experiments were conducted in the presence of a mixture of glutamatergic receptor antagonists (AMPA/kainate receptor antagonist DNQX plus NMDA receptor antagonist AP-5) to isolate inhibitory synaptic events. A high chloride intracellular solution was used to enhance resolution of SIPSCs. This causes a shift in the equilibrium potential of chloride to more positive values; thus, the inhibitory currents are inward going. $\boldsymbol{A}, \boldsymbol{D}$, Representative raw $10 \mathrm{~s}$ data traces in control (top) and in the presence of carbachol (50 $\mu \mathrm{m}$, middle) show that carbachol caused a large increase in the frequency and amplitude of sIPSCS. sIPSCs were completely blocked (lower trace) by the GABA receptor antagonist GABAzine, confirming that they are mediated by the activation of $\mathrm{GABA}_{\mathrm{A}}$ receptors. $\boldsymbol{B}, \boldsymbol{E}$, The cumulative probability histograms for the amplitudes of sIPSCS show a significant increase ( $p<0.001$, Kolmogorov-Smirnov two-sample test). $\boldsymbol{C}, \boldsymbol{F}$, The cumulative probability histograms for interevent intervals of sIPSCs show a significant increase $(p<0.001$, Kolmogorov-Smirnov twosample test). The inserts in $\boldsymbol{B}, \boldsymbol{C}, \boldsymbol{E}$, and $\boldsymbol{F}$ show the data for all recorded neurons (large $I_{\mathrm{h},} n=7 ;$ small $I_{\mathrm{h}}, n=6$ ). In both groups, there was a statistically significant increase in the frequency and amplitude of $\operatorname{sIPSCS}$ ( $p<0.05$, paired $t$ test).

$2.0 \mathrm{~Hz}$ ). In the presence of $20 \mu \mathrm{M}$ DNQX, $50 \mu \mathrm{M}$ AP-5 and $10 \mu \mathrm{M}$ GABAzine to block ionotropic glutamatergic and GABAergic receptors, these neurons responded to a $10 \mathrm{~s}$ train stimulation of blue light at $10 \mathrm{~Hz}$ with an inward current [Fig. $8 \mathrm{I} ;-21.3 \pm 2.4$ $\mathrm{pA}, n=32$ (13 large $I_{\mathrm{h}}$ neurons, 19 small $I_{\mathrm{h}}$ neurons)]. The current appeared after $2.6 \pm 0.4$ pulses (i.e., $260 \mathrm{~ms}$ ) reached a maximum after $29.8 \pm 4.5$ pulses $(\sim 300 \mathrm{~s})$ and decayed following the end of the light train with a time constant of $4.6 \pm 1.7 \mathrm{~s}$. The current response during the train exhibited some desensitization (Fig. 8I). The inward current at the end of the light train was statistically significantly different from the peak response (73.6 \pm $6.8 \%$ of peak; $p=0.0194$, paired $t$ test). In a control group, two current responses to $10 \mathrm{~s}$ light train stimulation $(10 \mathrm{~Hz}, 10 \mathrm{~ms}$ width pulse) separated by 5 min were similar in peak amplitude (first response, $-21.2 \pm 3.3 \mathrm{pA}$; second response, $-22.5 \pm 3.7 \mathrm{pA} ; p=0.643$, paired $t$ test; $n=9$ ) and charge within $10 \mathrm{~s}$ stimulation (first response, $-170.2 \pm$ $32.0 \mathrm{pC}$; second response, $-192.8 \pm 32.3$ $\mathrm{pC} ; p=0.3785$, paired $t$ test). To confirm that the release of acetylcholine was action potential dependent, we examined the response in the presence of $500 \mathrm{~nm}$ TTX. With TTX, the response to light train was completely blocked [peak amplitude: without TTX, $-16.3 \pm 3.6 \mathrm{pA}$; with TTX, $-0.12 \pm 0.46 \mathrm{pA} ; p=0.015$; charge within $10 \mathrm{~s}$ stimulation: without TTX, $-99.6 \pm 23.8 \mathrm{pC}$; with TTX, $2.6 \pm 1.2 \mathrm{pC}$; $p=0.012$, paired $t$ test; $n=5\left(1\right.$ large $I_{\mathrm{h}}$ neuron; 4 small $I_{\mathrm{h}}$ neurons)]. To examine whether this current response was due to the activation of muscarinic receptors by acetylcholine, we applied atropine $(5 \mu \mathrm{M})$ in the bath and tested its effect on the amplitude of the light-induced response. In the experimental group, putative GABAergic neurons were incubated with atropine $(5 \mu \mathrm{M})$ for $5 \mathrm{~min}$ after the first current response. With atropine, the response to the light train was significantly decreased [peak amplitude: without atropine, $-26.5 \pm 8.6 \mathrm{pA}$; with atropine, $-13.4 \pm 9.1 \mathrm{pA} ; p=0.027$; charge within $10 \mathrm{~s}$ stimulation: without atropine, $-172.5 \pm 39.2 \mathrm{pC}$; with atropine, $-67.7 \pm 35.4 \mathrm{pC} ; p=0.018$, paired $t$ test, $n=7$ (3 large $I_{\mathrm{h}}$ neurons; 5 small $I_{\mathrm{h}}$ neurons)]. As atropine did not completely block the response, we added the nicotinic receptor antagonist mecamylamine (100 $\mu \mathrm{M})$ to determine whether the atropineinsensitive component was due to activation of nicotinic receptors. In the presence of both atropine and mecamylamine, the response to the light train was completely blocked (peak amplitude: without atropine and mecamylamine, $-20.7 \pm 5.5 \mathrm{pA}$; with atropine and mecamylamine, $-0.77 \pm 0.57 \mathrm{pA} ; p=0.020$; charge within 10 s stimulation: without atropine and mecamylamine, $149.7 \pm 20.0 \mathrm{pC}$; with atropine and mecamylamine, $2.2 \pm$ $2.5 \mathrm{pC} ; p=0.0052$, paired $t$ test; $n=4$ ( 2 large $I_{\mathrm{h}}$ neurons, 2 small $I_{\mathrm{h}}$ neurons), supporting the idea that the inward current was mediated by the release of acetylcholine, and activation of both muscarinic and nicotinic receptors on BF GABAergic neurons.

\section{Discussion}

The BF represents the final node of the ventral arm of the brainstem ascending reticular activating system, and as such plays a critical role in activating the cortex during wakefulness and rapid eye movement (REM) sleep (Brown et al., 2012). Within the BF, both cholinergic and noncholinergic BF neurons play important roles in cortical activation and attention (Semba, 2000). Lesion studies in animals report pronounced deficits in cortical activation and attention following lesions of the BF, which are more 
profound when both cholinergic and noncholinergic neurons are lesioned, suggesting a synergistic role of cholinergic and noncholinergic BF neurons (Buzsaki et al., 1988; Kaur et al., 2008; Fuller et al., 2011). Among the noncholinergic neurons, neuroanatomical (Freund and Meskenaite, 1992; Gritti et al., 2003; Henny and Jones, 2008), electrophysiological recording (Duque et al., 2000; Hassani et al., 2009), and optogenetic studies (Kim et al., 2011) suggest that the BF GABAergic/PV ${ }^{+}$neurons may be particularly important in controlling neocortical fast activity, particularly in the gamma frequency $(30-80 \mathrm{~Hz})$ range. However, until now, the interaction between $\mathrm{BF}$ cholinergic and GABAergic/PV ${ }^{+}$neurons had not been investigated. Here we show that (1) cholinergic neurons and fibers were located in close proximity to identified BF GABAergic and PV neurons; (2) activation of cholinergic receptors increased synaptic transmission onto $\mathrm{BF}$ GABAergic/PV ${ }^{+}$neurons and strongly increased the firing rates; and (3) optogenetic release of acetylcholine from cholinergic neurons in situ excited putative GABAergic/PV ${ }^{+}$neurons.

Cholinergic and GABAergic cell bodies were found in close proximity in the medial portion of the mouse $\mathrm{BF}$, similar to previous findings in the rat (Gritti et al., 1993, 1997, 2003). In addition, many GABAergic neurons were located in lateral portions of the BF (McKenna et al., 2013), where much of the brainstem cholinergic input terminates (Woolf and Butcher, 1986; Semba et al., 1988). Cholinergic terminals, arising from local axon collaterals of $\mathrm{BF}$ cholinergic projection neurons or from brainstem inputs have been shown to terminate on noncholinergic neurons, including GABAergic neurons, in the rat (Záborszky et al., 1986; Martinez-Murillo et al., 1990; Záborszky and Duque, 2000). Heretofore, the subtype of GABAergic neuron targeted by cholinergic neurons had not been identified, however. Here, using dual fluorescent immunohistochemistry for vAChT and PV in GAD67-GFP knock-in mice, we observed that cholinergic terminals closely apposed GABAergic/PV neurons. These results suggest that acetylcholine, released from local axon collaterals of BF cholinergic neurons (Záborszky and Duque, 2000) or from brainstem cholinergic afferent inputs (Woolf and Butcher, 1986; Semba et al., 1988) is anatomically positioned to modulate the activity of cortically projecting $\mathrm{BF}$ GABAergic/PV neurons.

Consistent with a modulatory role for acetylcholine in the control of BF GABAergic/PV neuron activity were our pharma-

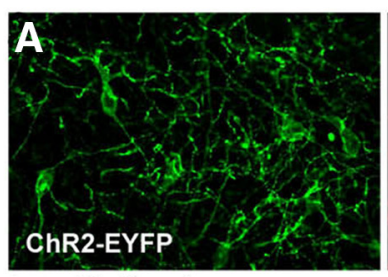

Cholinergic neuron

D
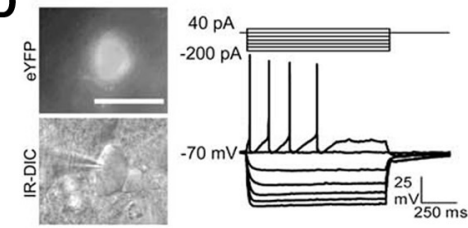
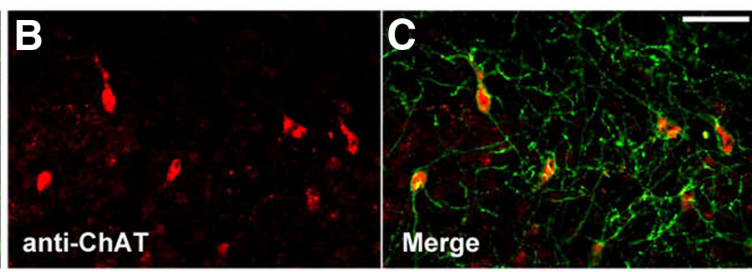

\section{E}
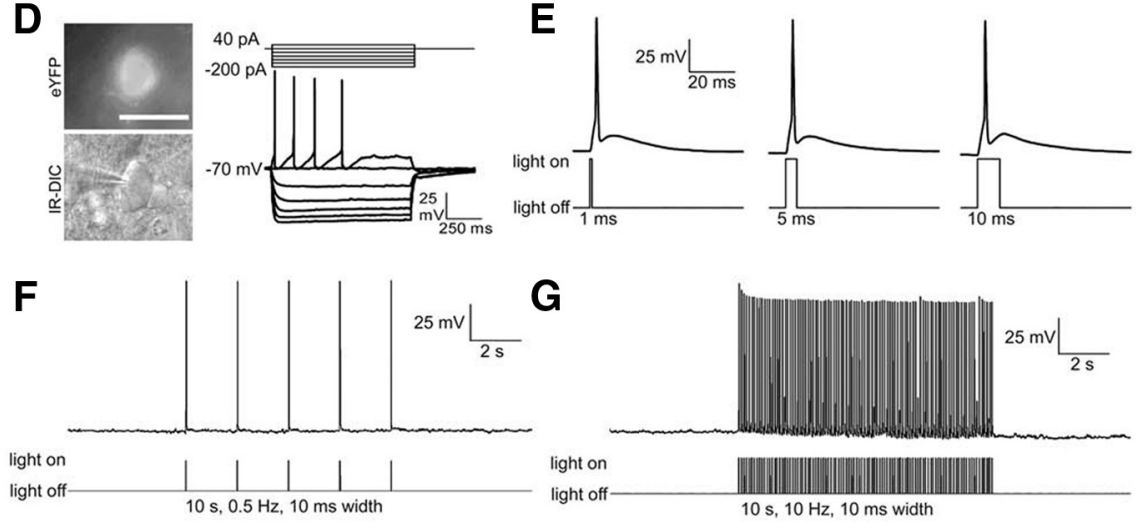

G

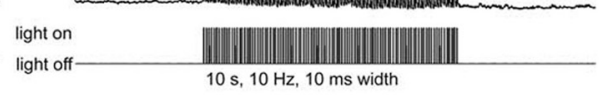

I
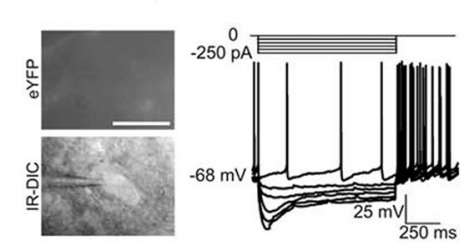

light on

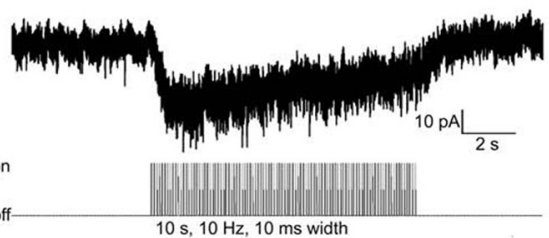

J
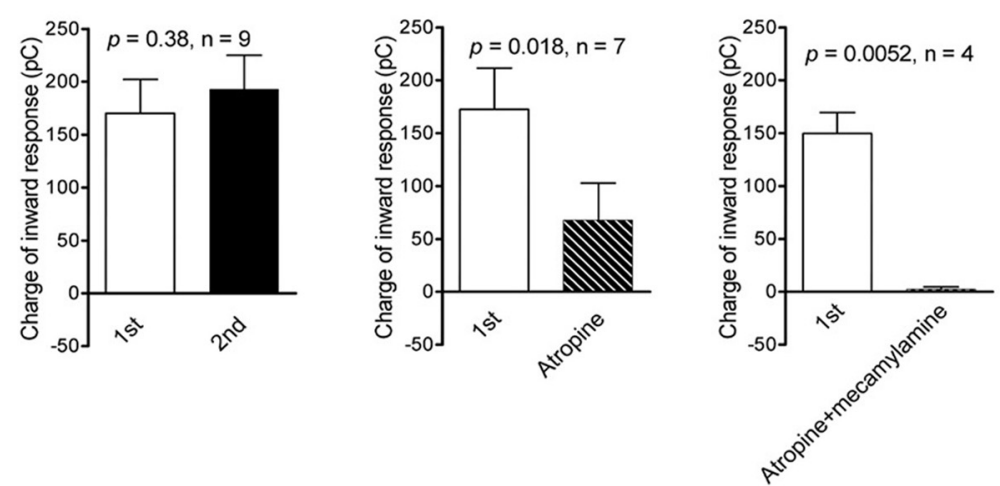

Figure 8. Optogenetic excitation of cholinergic neurons in ChAT-ChR2-EYFP mice causes an inward current in putative GABAergic neurons. $\boldsymbol{A}-\boldsymbol{C}$, Immunohistochemical staining for ChAT confirms that ChR2-EYFP is selectively localized to cholinergic neurons in ChAT-ChR2-EYFP mice. Scale bar, $50 \mu \mathrm{m}$. D, Intrinsic membrane properties of an EYFP ${ }^{+}$neuron. Scale bar, $25 \mu \mathrm{m}$. $\boldsymbol{E}-\boldsymbol{G}$, Cholinergic neurons are excited by light stimulation. EYFP ${ }^{+}$cholinergic neurons reliably follow a $5 \mathrm{~s}$ train of $10 \mathrm{~Hz}$ optical stimuli. $\boldsymbol{H}$, Intrinsic membrane properties of a putative GABAergic (EYFP ${ }^{-}$) neuron. $\boldsymbol{l}$, Optical stimulation induces an inward current in putative GABAergic neurons in the presence of AMPA, NMDA, and GABA receptor antagonists (20 $\mu \mathrm{m}$ DNQX plus $50 \mu \mathrm{m} A \mathrm{AP}-5$ plus $10 \mu \mathrm{m}$ GABAzine). Scale bar, $25 \mu \mathrm{m}$. J, Summary of the charge of the optically induced response in control ( $20 \mu \mathrm{m}$ DNQX plus $50 \mu \mathrm{m}$ AP-5 plus $10 \mu \mathrm{m}$ GABAzine), with a muscarinic receptor antagonist (atropine) and with a mixture of muscarinic plus nicotinic receptor antagonists (atropine plus mecamylamine). The optically induced inward current is reproducible when repeated at a 5 min interval, is partially blocked by $5 \mu \mathrm{m}$ atropine, and is completely blocked by a combination of $5 \mu \mathrm{m}$ atropine and $100 \mu \mathrm{m}$ mecamylamine. The $p$ value and the number of neurons tested (one neuron/animal) under each condition are given above each data bar. Paired $t$ test. IR-DIC, Infrared-differential interference contrast. cological experiments, which revealed for the first time that the cholinergic agonist carbachol strongly increased the firing rate of identified GABAergic and PV neurons with the size and intrinsic membrane properties corresponding to cortically projecting neurons (McKenna et al., 2013). Experiments with subtypeselective antagonists suggested that the excitatory effect of carba- 
chol on BF GABAergic neurons was due to activation of muscarinic $M_{1}$ and $M_{3}$ receptors. Interestingly, recent advances in pharmacology have identified selective $\mathrm{M}_{1}$-type receptor allosteric agonists, which show promise in preclinical models of Alzheimer's disease and schizophrenia (Conn et al., 2009; Digby et al., 2012). Our results suggest that one possible target of these agents is the BF GABAergic/PV projection to the cortex.

Previously, we showed that cortically projecting BF GABAergic/PV neurons can be subdivided into two subpopulations based on the amplitude and kinetics of their H-current (McKenna et al., 2013). Further evidence that these two subgroups likely represent functionally different subgroups was provided by our experiments in this study using selective muscarinic antagonists, which suggested that $M_{1}$ receptors mediated the effect of carbachol in most large $I_{\mathrm{h}}$ neurons, whereas $\mathrm{M}_{3}$ receptors mediated the effect on small $I_{\mathrm{h}}$ neurons. However, it should be noted that currently available muscarinic antagonists, such as the ones we used (pirenzepine and 4-DAMP) have relatively limited selectivity between $M_{1}$ and $M_{3}$ receptors and concentrations of antagonists required to block effects in brain slices are often much higher than the binding affinities of these drugs tested in expression systems would suggest. Thus, other approaches, such as testing the responses in M1/M3 knock-out animals, will be required in the future to definitely establish this difference. The functional significance of such a difference is unclear at present but it is of note that $M_{1}$ and $M_{3}$ receptors differentially couple to calcium and cAMP signaling (Burford et al., 1995), which may impact the prominent $\mathrm{H}$-currents of these neurons by altering their activation/deactivation kinetics (Biel et al., 2009) and thereby alter rhythmic firing by changing the depolarizing drive during the interspike/interburst interval. Thus, in addition to increasing the firing rate, acetylcholine may modulate the burst or cluster firing of identified GABAergic and PV neurons observed in vivo (Duque et al., 2000; Hassani et al., 2009).

Several lines of evidence suggested that the carbachol-induced postsynaptic excitation of BF GABAergic neurons was mediated mainly via activation of mixed cation currents, as follows: (1) in the majority of neurons, the reversal potential of the inward current was intermediate between the sodium and potassium reversal potentials; (2) the inward current was associated with an increase in membrane noise, suggesting increased channel opening; and (3) a reduction of extracellular sodium strongly reduced the amplitude of the current and shifted the reversal potential closer to the potassium equilibrium potential. However, in some neurons there was no clear reversal potential or a reversal close to the potassium equilibrium potential, suggesting an additional minor contribution of leak potassium currents. In addition to blocking the increase in firing rate by bath-applied carbachol, atropine also blocked the inward current. Together with the large size of the carbachol-induced inward current, these data suggest that the muscarinic receptor-mediated inward current is the main driver of the increase in firing rate caused by carbachol.

In addition to direct postsynaptic actions, recordings of spontaneous synaptic currents revealed that carbachol increased the frequency of both excitatory and inhibitory events. Thus, in addition to exciting GABAergic projection neurons, carbachol also increased the activity of local glutamatergic and GABAergic interneurons. However, miniature, action potentialindependent, synaptic currents were largely unaffected by carbachol, indicating that this effect is due to depolarization of local neurons rather than being due to a direct effect on the axon terminals themselves.
Direct support for an endogenous action of acetylcholine on BF GABAergic neurons was obtained through optical stimulation of cholinergic neurons in BF slice prepared from ChAT-ChR2EYFP mice. Light stimulation reliably elicited action potentials in cholinergic neurons and elicited an inward current in noncholinergic neurons with the same intrinsic membrane properties as cortically projecting GABAergic/PV neurons (McKenna et al., 2013). One caveat to these findings is that recent experiments have shown that the ChAT-ChR2-EYFP mice that we used here have enhanced acetylcholine release due to overexpression of the vesicular acetylcholine transporter (Kolisnyk et al., 2013). Thus, the magnitude of the inward current we recorded may have been increased due to increased release of acetylcholine in this strain. However, it is at present unclear whether this constitutive upregulation of acetylcholine release leads to compensatory downregulation of postsynaptic receptors. In fact, the magnitude of the inward current we recorded was less than that caused by bath application of carbachol. Thus, although we cannot make any conclusions about the magnitude of the cholinergic current in $\mathrm{BF}$ GABAergic neurons, our optogenetic results support our pharmacological and anatomical experiments, and suggest that release of acetylcholine in situ from cholinergic neurons can also excite BF GABAergic neurons. The light-induced current was partially blocked by atropine and completely blocked by a combination of atropine and mecamylamine, indicating that, in contrast to the inward current induced by bath-applied carbachol, nicotinic receptors are also involved. Presumably slow bath application of carbachol caused desensitization of the nicotinic receptors, whereas fast synaptic release of acetylcholine did not.

Our results here provide the first anatomical and physiological evidence for excitatory effects of cholinergic neurons on cortically projecting BF GABAergic neurons. Thus, the increased firing rate of these neurons during waking and REM sleep (Hassani et al., 2009) may be mediated by input from neighboring basal forebrain and/or brainstem cholinergic neurons. Furthermore, cortical activation deficits associated with neuronal loss in the BF observed in Alzheimer's disease (Grothe et al., 2012; Mesulam, 2012) may impair cortical activation not only via a loss of the cholinergic cortical projection but also via reduced activity of BF cortically projecting GABAergic neurons, due to either direct neuronal degeneration of these neurons or withdrawal of the cholinergic input. Similarly, the inhibition of BF cholinergic neurons by adenosine during sleep deprivation (Porkka-Heiskanen et al., 1997; Yang et al., 2013) may act to reduce the firing of cortically projecting BF GABAergic/PV neurons through a withdrawal of excitatory cholinergic input. Conversely, cholinergic agonists acting on nicotinic or $\mathrm{M}_{1} / \mathrm{M}_{3}$ receptors should be effective procognitive agents (Conn et al., 2009), not only due to their direct action on the cortex but also due to their excitation of the BF GABAergic/PV cortical projection.

\section{References}

Biel M, Wahl-Schott C, Michalakis S, Zong X (2009) Hyperpolarizationactivated cation channels: from genes to function. Physiol Rev 89:847885. CrossRef Medline

Brown RE, Basheer R, McKenna JT, Strecker RE, McCarley RW (2012) Control of sleep and wakefulness. Physiol Rev 92:1087-1187. CrossRef Medline

Burford NT, Tobin AB, Nahorski SR (1995) Differential coupling of m1, m2 and $\mathrm{m} 3$ muscarinic receptor subtypes to inositol 1,4,5-trisphosphate and adenosine $3^{\prime}, 5^{\prime}$-cyclic monophosphate accumulation in Chinese hamster ovary cells. J Pharmacol Exp Ther 274:134-142. Medline

Burk JA, Sarter M (2001) Dissociation between the attentional functions mediated via basal forebrain cholinergic and GABAergic neurons. Neuroscience 105:899-909. CrossRef Medline

Busch L, Borda E (2003) Castration decreases amylase release associated 
with muscarinic acetylcholine receptor downregulation in rat parotid gland. Br J Pharmacol 139:399-407. CrossRef

Buzsaki G, Bickford RG, Ponomareff G, Thal LJ, Mandel R, Gage FH (1988) Nucleus basalis and thalamic control of neocortical activity in the freely moving rat. J Neurosci 8:4007-4026. Medline

Cape EG, Jones BE (2000) Effects of glutamate agonist versus procaine microinjections into the basal forebrain cholinergic cell area upon gamma and theta EEG activity and sleep-wake state. Eur J Neurosci 12:21662184. CrossRef Medline

Chen L, McKenna JT, Leonard MZ, Yanagawa Y, McCarley RW, Brown RE (2010) GAD67-GFP knock-in mice have normal sleep-wake patterns and sleep homeostasis. Neuroreport 21:216-220. CrossRef Medline

Conn PJ, Jones CK, Lindsley CW (2009) Subtype-selective allosteric modulators of muscarinic receptors for the treatment of CNS disorders. Trends Pharmacol Sci 30:148-155. CrossRef Medline

Digby GJ, Noetzel MJ, Bubser M, Utley TJ, Walker AG, Byun NE, Lebois EP, Xiang Z, Sheffler DJ, Cho HP, Davis AA, Nemirovsky NE, Mennenga SE, Camp BW, Bimonte-Nelson HA, Bode J, Italiano K, Morrison R, Daniels JS, Niswender CM, et al (2012) Novel allosteric agonists of $M_{1}$ muscarinic acetylcholine receptors induce brain region-specific responses that correspond with behavioral effects in animal models. J Neurosci 32:85328544. CrossRef Medline

Duque A, Balatoni B, Detari L, Zaborszky L (2000) EEG correlation of the discharge properties of identified neurons in the basal forebrain. J Neurophysiol 84:1627-1635. Medline

Franklin KBJ, Paxinos G (2008) The mouse brain in stereotaxic coordinates, Ed 3. New York: Academic.

Freund TF, Meskenaite V (1992) gamma-Aminobutyric acid-containing basal forebrain neurons innervate inhibitory interneurons in the neocortex. Proc Natl Acad Sci U S A 89:738-742. CrossRef Medline

Fuller PM, Sherman D, Pedersen NP, Saper CB, Lu J (2011) Reassessment of the structural basis of the ascending arousal system. J Comp Neurol 519: 933-956. CrossRef Medline

Gritti I, Mainville L, Jones BE (1993) Codistribution of GABA- with acetylcholine-synthesizing neurons in the basal forebrain of the rat. J Comp Neurol 329:438-457. CrossRef Medline

Gritti I, Mainville L, Mancia M, Jones BE (1997) GABAergic and other noncholinergic basal forebrain neurons, together with cholinergic neurons, project to the mesocortex and isocortex in the rat. J Comp Neurol 383: 163-177. CrossRef Medline

Gritti I, Manns ID, Mainville L, Jones BE (2003) Parvalbumin, calbindin, or calretinin in cortically projecting and GABAergic, cholinergic, or glutamatergic basal forebrain neurons of the rat. J Comp Neurol 458:11-31. CrossRef Medline

Grothe M, Heinsen H, Teipel SJ (2012) Atrophy of the cholinergic basal forebrain over the adult age range and in early stages of Alzheimer's disease. Biol Psychiatry 71:805-813. CrossRef Medline

Hassani OK, Lee MG, Henny P, Jones BE (2009) Discharge profiles of identified GABAergic in comparison to cholinergic and putative glutamatergic basal forebrain neurons across the sleep-wake cycle. J Neurosci 29: 11828-11840. CrossRef Medline

Henny P, Jones BE (2008) Projections from basal forebrain to prefrontal cortex comprise cholinergic, GABAergic and glutamatergic inputs to pyramidal cells or interneurons. Eur J Neurosci 27:654-670. CrossRef Medline

Herrmann CS, Demiralp T (2005) Human EEG gamma oscillations in neuropsychiatric disorders. Clin Neurophysiol 116:2719-2733. CrossRef Medline

Jones CK, Byun N, Bubser M (2012) Muscarinic and nicotinic acetylcholine receptor agonists and allosteric modulators for the treatment of schizophrenia. Neuropsychopharmacology 37:16-42. CrossRef Medline

Kaur S, Junek A, Black MA, Semba K (2008) Effects of ibotenate and 192IgGsaporin lesions of the nucleus basalis magnocellularis/substantia innominata on spontaneous sleep and wake states and on recovery sleep after sleep deprivation in rats. J Neurosci 28:491-504. CrossRef Medline

Kim T, McKenna JT, McNally JM, Winston S, Yang C, Chen L, Kocsis B, Deisseroth K, Strecker RE, McCarley RW, Brown RE, Basheer R (2011) Optogenetic stimulation of parvalbumin-positive basal forebrain neurons entrains cortical gamma oscillations and promotes wakefulness. Soc Neurosci Abstr 37:286.215.

Kolisnyk B, Guzman MS, Raulic S, Fan J, Magalhães AC, Feng G, Gros R, Prado VF, Prado MA (2013) ChAT-ChR2-EYFP mice have enhanced motor endurance but show deficits in attention and several additional cognitive domains. J Neurosci 33:10427-10438. CrossRef Medline

Manns ID, Alonso A, Jones BE (2000) Discharge profiles of juxtacellularly labeled and immunohistochemically identified GABAergic basal forebrain neurons recorded in association with the electroencephalogram in anesthetized rats. J Neurosci 20:9252-9263. Medline

Martinez-Murillo R, Villalba RM, Rodrigo J (1990) Immunocytochemical localization of cholinergic terminals in the region of the nucleus basalis magnocellularis of the rat: a correlated light and electron microscopic study. Neuroscience 36:361-376. CrossRef Medline

McKenna JT, Yang C, Franciosi S, Winston S, Abarr KK, Rigby MS, Yanagawa Y, McCarley RW, Brown RE (2013) Distribution and intrinsic membrane properties of basal forebrain GABAergic and parvalbumin neurons in the mouse. J Comp Neurol 521:1225-1250. CrossRef Medline

McNally JM, McCarley RW, McKenna JT, Yanagawa Y, Brown RE (2011) Complex receptor mediation of acute ketamine application on in vitro gamma oscillations in mouse prefrontal cortex: modeling gamma band oscillation abnormalities in schizophrenia. Neuroscience 199:51-63. CrossRef Medline

Mesulam M (2012) Cholinergic aspects of aging and Alzheimer's disease. Biol Psychiatry 71:760-761. CrossRef Medline

Metherate R, Ashe JH (1993) Ionic flux contributions to neocortical slow waves and nucleus basalis-mediated activation: whole-cell recordings in vivo. J Neurosci 13:5312-5323. Medline

Metherate R, Cox CL, AsheJH (1992) Cellular bases of neocortical activation: modulation of neural oscillations by the nucleus basalis and endogenous acetylcholine. J Neurosci 12:4701-4711. Medline

Nicoll RA, Malenka RC, Kauer JA (1990) Functional comparison of neurotransmitter receptor subtypes in mammalian central nervous system. Physiol Rev 70: 513-565. Medline

Porkka-Heiskanen T, Strecker RE, Thakkar M, Bjorkum AA, Greene RW, McCarley RW (1997) Adenosine: a mediator of the sleep-inducing effects of prolonged wakefulness. Science 276:1265-1268. CrossRef Medline

Pressler RT, Inoue T, Strowbridge BW (2007) Muscarinic receptor activation modulates granule cell excitability and potentiates inhibition onto mitral cells in the rat olfactory bulb. J Neurosci 27:10969-10981. CrossRef Medline

Rye DB, Wainer BH, Mesulam MM, Mufson EJ, Saper CB (1984) Cortical projections arising from the basal forebrain: a study of cholinergic and noncholinergic components employing combined retrograde tracing and immunohistochemical localization of choline acetyltransferase. Neuroscience 13:627-643. CrossRef Medline

Semba K (2000) Multiple output pathways of the basal forebrain: organization, chemical heterogeneity, and roles in vigilance. Behav Brain Res 115: 117-141. CrossRef Medline

Semba K, Reiner PB, McGeer EG, Fibiger HC (1988) Brainstem afferents to the magnocellular basal forebrain studied by axonal transport, immunohistochemistry, and electrophysiology in the rat. J Comp Neurol 267:433453. CrossRef Medline

Shen KZ, Johnson SW (2000) Presynaptic dopamine D2 and muscarine M3 receptors inhibit excitatory and inhibitory transmission to rat subthalamic neurones in vitro. J Physiol 525:331-341. CrossRef Medline

Tamamaki N, Yanagawa Y, Tomioka R, Miyazaki J, Obata K, Kaneko T (2003) Green fluorescent protein expression and colocalization with calretinin, parvalbumin, and somatostatin in the GAD67-GFP knock-in mouse. J Comp Neurol 467:60-79. CrossRef Medline

Teipel SJ, Meindl T, Grinberg L, Grothe M, Cantero JL, Reiser MF, Möller HJ, Heinsen H, Hampel H (2011) The cholinergic system in mild cognitive impairment and Alzheimer's disease: an in vivo MRI and DTI study. Hum Brain Mapp 32:1349-1362. CrossRef Medline

Woolf NJ, Butcher LL (1986) Cholinergic systems in the rat brain: III. Projections from the pontomesencephalic tegmentum to the thalamus, tectum, basal ganglia, and basal forebrain. Brain Res Bull 16:603-637. CrossRef Medline

Yang C, Franciosi S, Brown RE (2013) Adenosine inhibits the excitatory synaptic inputs to basal forebrain cholinergic, GABAergic, and parvalbumin neurons in mice. Front Neurol 4:77. CrossRef Medline

Záborszky L, Duque A (2000) Local synaptic connections of basal forebrain neurons. Behav Brain Res 115:143-158. CrossRef Medline

Záborszky L, Heimer L, Eckenstein F, Leranth C (1986) GABAergic input to cholinergic forebrain neurons: an ultrastructural study using retrograde tracing of HRP and double immunolabeling. J Comp Neurol 250:282-295. CrossRef Medline

Zhao S, Ting JT, Atallah HE, Qiu L, Tan J, Gloss B, Augustine GJ, Deisseroth K, Luo M, Graybiel AM, Feng G (2011) Cell type-specific channelrhodopsin-2 transgenic mice for optogenetic dissection of neural circuitry function. Nat Methods 8:745-752. CrossRef Medline 